Article

\title{
SNUXH: A Set of Social Network User Experience Heuristics
}

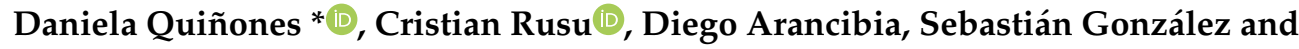 \\ María Josée Saavedra
}

School of Informatics Engineering, Pontificia Universidad Católica de Valparaíso, Valparaíso 2340000, Chile; cristian.rusu@pucv.cl (C.R.); diego.arancibia.c01@mail.pucv.cl (D.A.); sebastian.gonzalez.c@mail.pucv.cl (S.G.); maria-josee.saavedra.c@mail.pucv.cl (M.J.S.)

* Correspondence: daniela.quinones@pucv.cl

Received: 27 August 2020; Accepted: 17 September 2020; Published: 19 September 2020

check for updates

\begin{abstract}
With the growth and overcrowding of the internet, the use of online social networks has been increasing. Currently, social networks are used by a wide variety of users-with different objectives and in different contexts of use-, so it is essential to design intuitive and easy to use social network applications that generate a positive user experience (UX). The heuristic evaluation is a well-known evaluation method that allows detecting usability problems; a group of experts evaluates a product and/or system using a set of heuristics as a guide. Although the heuristic evaluation is oriented to evaluate the usability, it can be useful to evaluate other aspects related to the UX. Due to the specific features of social networks, it is necessary to have a specific set of heuristics to evaluate them. Sets of specific heuristics for social networks have been proposed, but they focus on evaluating the only usability. This article presents a set of heuristics that attend not only usability issues, but other UX factors as well, social network user experience heuristics (SNUXH). The new set of heuristics was developed, validated, and refined in four iterations. The results obtained in the experimental validation indicate that the SNUXH set is useful and more effective than generic heuristics (Nielsen's heuristics) when evaluating social networks.
\end{abstract}

Keywords: user experience; usability; social networks; heuristic evaluation; heuristics; experimental validation

\section{Introduction}

Nowadays, social networks are part of people's daily lives. In a study conducted by GlobalWebIndex in 2018 to 113,932 users from several countries [1], it was concluded that $98 \%$ of digital consumers are social media users, and adoption is high even among 55-64 years (94\%). Social networks have evolved into multimedia platforms, and for this reason, users are now as likely to use them for keeping up with the news ( $40 \%$ of users) to stay in touch with friends ( $40 \%$ of users). On the other hand, $36 \%$ of users use social networks for entertainment. In a lower percentage, users also use social networks to share photos or videos with others (33\%), to research/find products to buy (29\%), to share their opinions (29\%), and to create networks for work (23\%). In the same report, it is showed that the most popular social platforms are Facebook (with an $85 \%$ of users with an account created on Facebook); followed by YouTube (79\% of users), Facebook messenger (72\% of users), and WhatsApp (66\% of users). According to the study, there are 20 most used social networks.

It is a fact that social networks are widely used. A social network can be defined as a social structure formed by people or entities connected and linked together by some type of relationship or common interest [2]. We can maintain this social network using devices, such as smartphones, laptops, tablets, etc., and applications. There is a large variety of social networks, and users use those 
that meet their expectations; social networks that allow them to perform the tasks they want to do (sell products, share with users, read the news, etc.), and social networks where the interaction to be intuitive and pleasant, generating a good experience. If a social network is difficult to use or the users do not understand how to use it, they can get frustrated and look for another one. If the use of a social network evokes negative experiences among users, it will hinder the product's success on the market [3]. It is important to detect problems that prevent users from performing their tasks in a simple and intuitive way, and to understand what emotions are important for them in the interaction.

In this sense, it is crucial to evaluate the usability and the experience that users have when using social networks, detect problems that may generate negative experiences, and correct them to generate greater user satisfaction. One of the most used methods to evaluate usability is the heuristic evaluation [4], which detects usability problems using usability heuristics [5]. Although the heuristic evaluation is oriented to evaluate the usability, it can be useful to evaluate other aspects related to the user experience (UX) [6-9]. UX is not the same as usability. The UX is composed of several dimensions, such as accessibility, communicability, usability, among others. Thus, usability is part of UX, and depending on the set of heuristics used, it is possible to evaluate both usability and UX. In this sense, several authors have developed heuristics to evaluate UX aspects [9]. Well-known Nielsen's heuristics [10] are widely used to evaluate applications in a general way. However, social networks have specific features that differentiate them from other applications, so a generic set of heuristics may not be effective in detecting specific usability/UX problems [6,11,12].

Sets of heuristics have been proposed to evaluate social networks [13-15]. However, these sets focus on evaluating usability $[13,15]$ or specific features for a particular discipline (security and health-oriented social networks [14]) so other relevant aspects related to the UX are not evaluated with the existing heuristics. In this article, we present $\mathrm{SNUXH}$-a set of user experience heuristics for social networks. The set was proposed to evaluate several aspects of the UX, including usability. The heuristics were developed in four iterations using the methodology proposed by Quiñones et al. [6,7] and were specified, including 13 elements: id, priority, name, definition, explanation, social network feature, examples, benefits, problems, checklist, usability attribute related, UX attribute related, and set(s) of existing heuristics related. SNUXH was validated and refined through several experiments with experts (expert judgment and heuristic evaluation) and users (co-discovery test). The version of SNUXH developed in the third iteration can be reviewed in Reference [16] with preliminary validation results.

This article is organized as follows: Section 2 explores the theoretical background; Section 3 briefly explains the methodology applied to develop SNUXH; Section 4 shows the process followed to develop SNUXH; Section 5 explains the SNUXH validation and results; Section 6 presents the final set of SNUXH; and Section 7 presents the conclusions and future works.

\section{Theoretical Background}

The concepts of social network, UX, usability, and heuristic evaluation are briefly presented below. In addition, related work is described.

\subsection{Social Networks}

A social network is a social structure formed by people or entities connected and linked together by some type of relationship or common interest [2]. Currently, a social network is related to websites or mobile applications used by users to connect with people with common interests. This "online" social network provides services through the Internet and allows users to generate a public profile; include data and personal information; and interact with other users using different tools depending on the type of network [17]. Users can build a public (or semipublic) profile within a delimited social network [18], manage a list of other users with whom they have a connection, and thus, share experiences, content, images, videos, among others. The nature of interactions between users differs between different types of social networks (Facebook, Instagram, Twitter, LinkedIn, YouTube, etc.). According to the ONTSI [19], social networks are classified into two large groups: direct and indirect. 
On the one hand, in direct social networks, there is a collaboration between people who share common interests. Users interact with each other on equal terms and can control the information they share. Users create profiles through which they manage their personal information, their degree of privacy, and the relationship with other users (e.g., Facebook, YouTube, Twitter). Direct social networks are classified according to four approaches: (1) Purpose (leisure or professional use); (2) Mode of operation (of content, based on personal or professional profiles, or microblogging); (3) Degree of openness (public or private); and (4) Level of integration (vertical or horizontal integration). On the other hand, in indirect social networks, users do not usually have a visible profile for everyone. There is an individual or group that controls and directs information or discussions around a specific topic. Indirect social networks are classified into forums and blogs (e.g., Reddit, 9gag).

A social network can be classified into more than one type. For example, Twitter is a type of direct social network that can be of leisure or professional use (according to its purpose) and also public (according to its degree of openness). Depending on the type of social network, these may have different functionalities and features. However, all online social networks share the following six features $[2,17,19,20]$ :

1. Security: Social network must maintain the confidentiality, integrity, and availability of data (personal information, images, videos, etc.), avoiding unauthorized access.

2. Connectivity: Social network allows users to establish links with other people, generating different types of connections. The social network provides tools for users to manage their contacts, their relationships, and maintain contact with other users.

3. Interaction: Through the social network, the user can interact and relate to each other through different mechanisms (audio, video, text). Social network allows users to share content and experiences.

4. Customization: Users can adjust different configurations of the social network based on their interests and needs. For example: Profile personalization, notification, permissions, language, interface settings, etc.

5. Content management: Social network provides tools to users to manage the content and information they wish to display and visualize within their network space, independently if other users will interact with it or not.

6. Help Center: Social network offers users a help service to solve problems or doubts about its use and functionalities.

\subsection{User Experience and Usability}

UX refers to "person's perceptions and responses resulting from the use and/or anticipated use of a product, system or service" [21]. UX includes all the emotions, beliefs, preferences, perceptions, physical and psychological responses, behaviors, and achievements of users that occur before, during, and after use [21]. UX involves how the user feels when using a product or how they will feel when using a product in the future. The UX is different for each user, so it is crucial to know who the users that will use the product are, their features, needs, and what motivates them to interact with a specific product. It is very important to try to meet the majority of potential users.

Several factors influence the UX, and different authors have proposed various models to describe the UX. Peter Morville [22] proposes seven factors that influence the UX: useful, usable, desirable, findable, accessible, credible, and valuable. Morville states that the core of the UX is that users find a value to what is being provided to them. On the other hand, Arhippainen and Tähti [23] decompose the UX into several factors classified into five groups: specific user factors, social factors, cultural factors, the context of use factors, and product factors. For Kankainen [24], the UX is the result of a motivated action in a specific context, which is influenced by the user's expectations and previous experiences. The above influences the user's current experience, and with it, their expectations and 
future experiences. Each proposal is different, and which one to use will depend on the type of product (system or service), its purpose, the context of use, and the type of user.

As described by Morville proposal [22], usability is part of the UX, and they are not the same. Usability is a quality attribute and is defined as "the extent to which a product can be used by specified users to achieve specified goals with effectiveness, efficiency, and satisfaction in a specified context of use" [21]. The ISO 9241 standard [21] states three attributes for usability: effectiveness, efficiency, and satisfaction. Since usability is part of the UX, then UX extends these three usability attributes [25]. On the other hand, Nielsen [26] proposes five attributes: learnability, efficiency, memorability, errors, and satisfaction. Although the UX is a broader concept than usability, evaluating usability also evaluates the UX partially. For the development of SNUXH, we used the UX factors proposed by Morville [22], and the usability attributes proposed by the ISO 9241 standard [21]. The reason for this selection is explained in detail in Section 3.

\subsection{Heuristic Evaluation}

There are many methods for evaluating usability and UX. The AllaboutUX website gathers more than 80 evaluation methods [27]. In general, the evaluation methods are classified as follows:

1. Inspection methods: Methods in which expert evaluators (no users) inspect a product, system, or service to detect usability/UX problems. These inspections can be carried out before, during, and/or after the product development. These methods include: Heuristic evaluation, cognitive walkthrough, formal inspections [28], among others.

2. Test methods: Methods in which end users participate. Users interact with a product, system, or service to gather relevant information about usability/UX problems. These methods include: thinking aloud [29], co-discovery [30], emocards [31], among others.

Heuristic evaluation is an inspection method proposed by Nielsen and Molich [5,29]. This method involves having between 3 and 5 expert evaluators who examine a user interface to find (potential) usability/UX problems and judge its compliance with recognized usability principles ("heuristics"). Heuristics are "general rules that seem to describe common properties of usable interfaces" [10,32]. Depending on the set of heuristics used, it is possible to evaluate both usability and other attributes related to the UX [6-9].

Nielsen proposed 10 general usability heuristics $(\mathrm{NH})$ for evaluating the interaction design [10]: NH1: Visibility of system status; NH2: Match between system and the real world; NH3: User control and freedom; NH4: Consistency and standards; NH5: Error prevention; NH6: Recognition rather than recall; NH7: Flexibility and efficiency of use; NH8: Aesthetic and minimalist design; NH9: Help users recognize, diagnose, and recover from errors; and NH10: Help and documentation.

Nevertheless, Nielsen's heuristics [10] may be too generic to evaluate specific application domains [11]. For this reason, several authors have proposed new sets of usability/UX heuristics to evaluate different domains considering those specific features that differentiate them from other domains [11,12]. Two systematic reviews [11,12] analyze in detail the process of development and validation of new sets of heuristics. Most authors establish a new set of usability/UX heuristics adapting existing heuristics and creating new heuristics to evaluate specific features of the domain, in addition to usability/UX attributes. Other authors apply a methodology to establish and validate a new set of heuristics [11]. 


\subsection{Related Work}

Esteves et al. [13] propose eight usability heuristics oriented to social networks (EH). Each heuristic has a name and a brief explanation. The heuristics were developed based on usability problems and heuristics for virtual worlds. The set evaluates relevant features of social networks, such as: The disclosure of personal data, visualization of user information, and interaction. However, it does not consider general aspects (or elements) of any application, such as "aesthetic and minimalist design" (Nielsen's heuristics [10]), does not have heuristics to evaluate the creation or publication of content, and does not present experimental validation.

Yeratziotis et al. [14] present 11 heuristics to evaluate the security of social networks (Online Health Social Networking, YH). Although they present an interesting set of heuristics, the proposal focuses on a specific type of social networks for health, which makes it difficult to evaluate online social networks more generally.

Dubois [15] presents an interesting and complete analysis of social networks and their relationship with psychology (psychosocial components). It proposes a method of evaluating usability in social networks through heuristics with specific metrics, grouped in categories. However, this study does not present a set of heuristics with a name and definition, but proposes aspects and categories to be evaluated using checklists, which makes it difficult to use in a heuristic evaluation.

\section{Methodology Applied to Establish SNUXH}

Even though there are several sets of heuristics to evaluate specific application domains [11,12], there are few formal methodologies to develop and validate new heuristics [6,33-38]. The heuristics' validation process is a critical task to determine if the new set allows detecting both general and specific usability/UX problems related to the domain [11,12].

We developed SNUXH using the methodology proposed by Quiñones et al. [6,7]. We decided to apply this methodology since we consider that its stages are well explained and that it proposes concrete methods of heuristics' validation (both quantitative and qualitative methods). Although other methodologies are interesting, some of them do not explain in detail how to apply the proposed stages [33-36], or do not propose quantitative and qualitative validation methods that allow evaluating the effectiveness of the heuristics [33,36-38].

The methodology used has eight stages that can be applied iteratively to refine and improve the new set of heuristics proposed. The methodology allows developing heuristics to evaluate the usability and other attributes related to the UX. Each stage of the methodology presents: (1) A definition; (2) the inputs that are needed to start the stage; (3) the activities that are performed in the stage; (4) the outputs that are obtained at the end of the stage; and (5) a BPMN diagram that shows the activities of the graphically stage. The methodology stages are shown in Table 1. 
Table 1. Stages of the methodology proposed by Quiñones et al. (adapted from References [6,7]).

\begin{tabular}{|c|c|c|}
\hline Step & Name & Definition \\
\hline 1 & Exploratory stage & $\begin{array}{l}\text { Perform a literature review to collect } \\
\text { information about the specific domain, their } \\
\text { features, the usability/UX (user experience) } \\
\text { attributes, and existing set of heuristics } \\
\text { (and/or other relevant elements). }\end{array}$ \\
\hline 2 & Experimental stage & $\begin{array}{l}\text { Analyze data that are obtained in different } \\
\text { experiments to collect additional } \\
\text { information that has not been identified in } \\
\text { the previous stage. }\end{array}$ \\
\hline 3 & Descriptive stage & $\begin{array}{l}\text { Select and prioritize the most important } \\
\text { topics of all information that was collected } \\
\text { in the previous stages. }\end{array}$ \\
\hline 4 & Correlational stage & $\begin{array}{l}\text { Match the features of the specific } \\
\text { application domain with the usability/UX } \\
\text { attributes and existing heuristics (and/or } \\
\text { other relevant elements). }\end{array}$ \\
\hline 5 & Selection stage & $\begin{array}{l}\text { Keep, adapt, and/or discard the existing sets } \\
\text { of usability/UX heuristics that were selected } \\
\text { in Step } 3 \text { (and/or other relevant elements). }\end{array}$ \\
\hline 6 & Specification stage & $\begin{array}{l}\text { Formally specify the new set of usability/UX } \\
\text { heuristics using a standard template. }\end{array}$ \\
\hline 7 & Validation stage & $\begin{array}{l}\text { Validate the set of heuristics through } \\
\text { several experiments (heuristic evaluations, } \\
\text { expert judgments, user tests) in terms of } \\
\text { their effectiveness and efficiency in } \\
\text { evaluating the specific application. }\end{array}$ \\
\hline 8 & Refinement stage & $\begin{array}{l}\text { Refine and improve the new set of } \\
\text { heuristics based on the feedback that was } \\
\text { obtained in Step } 7 .\end{array}$ \\
\hline
\end{tabular}

\section{Applying the Methodology to Establish SNUXH}

We established SNUXH through four iterations. Figure 1 shows the stages applied in each iteration. Iterations are marked as "It. N".

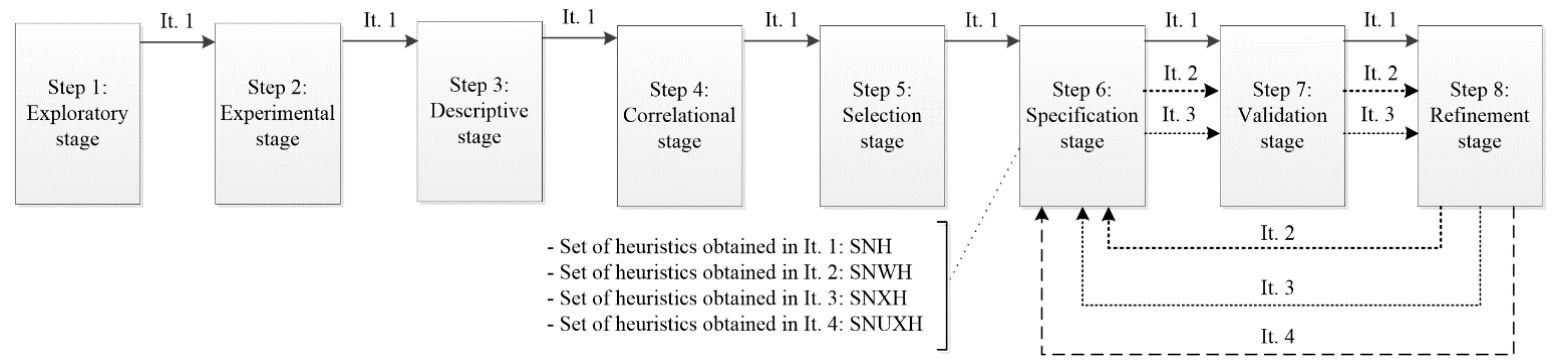

Figure 1. Iterations and stages are performed to establish social network user experience heuristics (SNUXH).

In iteration 1, all stages were performed, and the heuristics were developed and validated. Iterations 2, 3, and 4 mainly focused on validating and improving the set of heuristics. The detail of inputs, outputs, and activities performed in each step can be reviewed in Appendix A (first iteration), Appendix B (second iteration), Appendix C (third iteration), and Appendix D (fourth iteration). Appendix $\mathrm{E}$ shows the set of heuristics for social networks developed at each iteration. Each set has been abbreviated differently for each iteration: SNH (first version, iteration 1), SNWH (second version, 
iteration 2), SNXH (third version, iteration 3), and SNUXH (final version, iteration 4). Iterations performed are explained below.

\subsection{First Iteration}

In the first iteration, all stages were performed. In "Step 1: Exploratory stage", we conducted a literature review to collect information about: Social networks and features (see Sections 2 and 2.1); usability/UX attributes (see Sections 2 and 2.2); and existing set of heuristics (see Sections 2 and 2.4). We performed the activities proposed in the methodology $[6,7]$ for conducting the literature review. In "Step 2: Experimental stage", we performed a heuristic evaluation of Facebook using three sets of heuristics (Nielsen [10], Esteves et al. [13], and Yeratziotis et al. [14]). Based on the results, we: (1) Analyzed how each set cover (or not cover) the usability/UX problems detected by evaluators; (2) analyzed correct/incorrect associations among problems and heuristics; (3) detected heuristics with unclear definitions; and (4) identified what heuristics are necessary to create to evaluate specific features of social networks not evaluated by the existing sets. For more detail about the results obtained in the experiment performed, see Appendix F.

In "Step 3: Descriptive stage", we grouped the information collected in steps 1 and 2 (features of social networks, usability/UX attributes, existing sets of heuristics, usability/UX problems), and we sorted and prioritized the information of each topic using a three-level scale. Finally, based on the value assigned, we selected the next information to develop the heuristics: Six social network features (security, connectivity, interaction, customization, content management, help center); three usability attributes (effectiveness, efficiency, satisfaction); five UX attributes (useful, usable, desirable, findable, credible); and three existing sets of heuristics (Nielsen [10], Esteves et al. [13], and Yeratziotis et al. [14]). The detail of selected information can be reviewed in Appendix G. In "Step 4: Correlational stage", we matched the social network features, usability/UX attributes, and existing sets of heuristics. Only the "Help center" feature is completely covered by the existing sets of heuristics; while the "Security" feature is partially covered. The features "Connectivity", "Interaction", "Customization", and "Content management" are slightly covered, so it is necessary to create new heuristics to evaluate these features. We decided not to group the heuristics into categories. For more detail about the matching process, see Appendix $\mathrm{H}$.

In "Step 5: Selection stage", using the three existing sets of heuristics selected in step $3[10,13,14]$, we kept zero heuristics without changes; adapted 25 heuristics to evaluate both general and specific features; and discard nine heuristics (since they did not fit to evaluate social networks). We created one new heuristic for evaluating the specific social network feature "Content management". For more details about the selection process, see Appendix I. In "Step 6: Specification stage", we proposed the first version of social network heuristics (SNH, see Appendix E). This version included 16 heuristics, and the template proposed in the methodology was used for its specification, including all elements except the "checklist" item ("checklist" was added in the second iteration).

In "Step 7: Validation stage", we validated the first version of heuristics through heuristic evaluations, analyzing Facebook. Evaluations were carried out by two separate groups of evaluators, in equal conditions. Each group was composed of three evaluators, of a similar level of expertise. One group used only the SNH set (experimental group), while the other group used only Nielsen's heuristics [10] (control group). All evaluators have moderate to high expertise in HCI and have experience performing heuristic evaluations (they performed a heuristic evaluation on a regular basis). The results obtained by the two groups were then compared. The details of heuristic evaluations performed, and results obtained are presented in Sections 2.1 and 5. Finally, in "Step 8: Refinement stage", we refined the heuristics based on the results and feedback obtained in step 7 . We refined and improved all heuristics and eliminated two heuristics. We decided to perform a second iteration, repeating steps 6, 7, and 8. For more detail about the refinements performed, see Appendix J. 


\subsection{Second Iteration}

In the second iteration, we performed steps 6, 7, and 8. In "Step 6: Specification stage", we proposed the second version of social network heuristics (SNWH, see Appendix E). This second version included 14 heuristics, and we completed the entire template, adding checklists. In addition, we improved the specification of each heuristic and eliminated the heuristics "SNH2: Visibility of system elements and important information" and "SNH6: Consistency in design and web symbology", since these heuristics were similar to SNH1 and SNH5.

In "Step 7: Validation stage", we validated the second version of heuristics (SNWH) through expert judgment. We surveyed the three evaluators who participated in the heuristic evaluation performed in the previous iteration and who used the SNH set. We asked them about the utility, clarity, ease of use, and need for additional elements of SNWH to evaluate social networks. The results obtained are presented in Sections 2.2 and 5. Finally, in "Step 8: Refinement stage", we refined the heuristics based on the results and feedback obtained in step 7 . We refined eight heuristics, eliminated two heuristics, joined two heuristics into one, and create two heuristics. We decided to perform the third iteration, repeating steps 6,7 , and 8 to validate if the changes performed improve the effectiveness of SNWH. For more detail about the refinements performed, see Appendix K.

\subsection{Third Iteration}

In the third iteration, we performed once again steps 6, 7, and 8. In "Step 6: Specification stage", we proposed the third version of social network heuristics (SNXH, see Appendix E). This third version included 12 heuristics, improving the heuristics specification. We presented the SNXH version of the third iteration in Reference [35], including the ID, name, and description for the 12 heuristics. In Reference [16], we present the heuristics proposed in the third iteration, with preliminary validation results.

In "Step 7: Validation stage", we validated the third version of heuristics (SNXH) through user tests and expert opinion. We performed a Co-discovery test to: (1) Validate that the problems identified in the heuristic evaluation (first iteration) are perceived as real problems for the users, and (2) identify new usability/UX problems that arise in the test (not detected in the heuristic evaluation), and then review if these problems are evaluated by the SNXH set. The test was designed to evaluate Facebook in its desktop application (website version). A total of eight users participated in the test forming four groups (two users per group). The participants were undergraduate students of the School of Informatics Engineering of the Pontificia Universidad Católica de Valparaíso (PUCV), Chile. All the participants had knowledge of the use of websites and the social network Facebook. The experiments were performed in the usability laboratory of the School of Informatics Engineering.

In addition, we conducted an expert opinion to validate if the SNXH set is correctly specified. We asked two experts in HCI what they think about the SNXH set. Based on the feedback obtained, the SNXH set was refined. All the comments and recommendations were taken into account to improve the set. The detail of the results obtained in both the Co-discovery test and the expert opinion is presented in Sections 2.3 and 5.

Finally, in "Step 8: Refinement stage", we refined the heuristics based on the results and feedback obtained in step 7. We refined four heuristics, eliminated one heuristic, separate one heuristic into two, and create four heuristics. We decided to perform a final iteration, repeating step 6 to propose the final version of SNXH. For more detail about the refinements performed, see Appendix L.

\subsection{Fourth Iteration}

In the fourth and final iteration, we performed step 6 to prepare the final version of SNUXH. In "Step 6: Specification stage", we proposed the fourth version of social network heuristics (SNUXH, see Appendix E). This version included 14 heuristics, improving the heuristics specification. We refined 
the heuristics based on the results obtained in validations performed in the third iteration. The final version of SNUXH is presented in Section 6.

\section{Validation of SNUXH}

The validation of a new set of usability/UX heuristics is one of the most complex tasks identified by several authors $[4,11,12]$. The methodology applied to develop SNUXH proposes three validation methods: heuristic evaluation, expert judgment, and user tests [6,7]. We experimentally validated SNUXH in three iterations using the three methods proposed. The results of each iteration are described below.

\subsection{First Iteration: Validation through Heuristic Evaluations}

We selected six evaluators to perform a heuristic evaluation to evaluate $\mathrm{SNH}$ against a set of control heuristics (Nielsen's heuristics, NH [10]). We decided to use Nielsen's heuristics as control heuristics, given the results obtained in the "Step 2: Experimental stage". In step 2, a heuristic evaluation was performed using three sets of heuristics $[10,13,14]$. Of the three sets, NH obtained better results in terms of correct associations and a number of covered problems related to social networks. An association is correct when the unfulfilled heuristic is properly linked to the identified usability/UX problem. The researcher must perform a critical and constructive analysis of the results and determine if the association of problems with heuristics was correct or incorrect. For more detail, see Appendix F.

Facebook was evaluated (in its 210-240 version). We decided to use Facebook as a case study since it is one of the most used social networks [1]. The protocol of the heuristic evaluation proposed by Nielsen was followed [5,32]. Facebook was evaluated by two separate groups of evaluators of similar experience under the same conditions. One group uses only the SNH set (three evaluators, experimental group), while the second group uses only NH set [10] (three evaluators, control group). The groups worked separately. Then, the usability/UX problems identified by the two groups were compared to evaluate the effectiveness of SNH in terms of five criteria $[6,7]$. The description and formula of the criteria are presented in Table 2. As stated in the methodology [6,7], SNH performs well, and it is an effective instrument when better results than the control heuristics are obtained in terms of (1), (2), (3), (4), and (5) criteria.

Table 3 shows the results obtained in the heuristic evaluations performed by both experimental and control groups. In addition, the effectiveness of SNH in terms of the five criteria is shown. As shown in Table 3, SNH obtained better results than $\mathrm{NH}$ in the five criteria, indicating that they work better and are more effective. SNH detected more usability/UX problems than $\mathrm{NH}$, and moreover, detected more specific, severe, and critical problems.

In both evaluations, $\mathrm{SNH}$ and $\mathrm{NH}$ had associated at least one usability/UX problem, except the heuristic "SNH9: Minimize the user's memory load" of SNH set, which had zero associated problems. The specification of SNH9 should be reviewed and determine why it has no associated problems. The heuristics with more incorrect associations for SNH set were: "SNH4: Match between system and the real world", "SNH5: Consistency and standards between system elements", and "SNH6: Consistency in design and web symbology". It is necessary to review and improve the specification of these heuristics. However, it is important to notice that the percentage of incorrect associations obtained for $\mathrm{SNH}$ is lower than for NH. After analyzing the results, each heuristic for SNH set was reviewed to improve its specification. 
Table 2. Five criteria for evaluating the effectiveness of a new set of usability/UX heuristics (adapted from References [6,7]).

\begin{tabular}{|c|c|}
\hline Criterion Description & Formula \\
\hline $\begin{array}{l}\text { (1) Numbers of correct and incorrect associations of } \\
\text { problems to heuristics }\end{array}$ & $\begin{array}{l}C A=\frac{\sum_{n=1}^{T} C A H n}{T P} \times 100 \\
I A=\frac{\sum_{n=1}^{T} I A H n}{T P} \times 100 \\
\text { where: } \\
\text { - } \quad C A: \text { correct associations } \\
\text { - } \quad I A: \text { incorrect associations } \\
\text { - } \quad \text { : total number of heuristics of the set } \\
\text { - } \quad \text { CAHn: number of correct associations of the } \\
\text { problems to the heuristic " } n \text { " } \\
\quad \text { IAHn: number of incorrect associations of the } \\
\quad \text { problems to the heuristic " } n \text { " } \\
\text { - TP: total usability/UX problems identified }\end{array}$ \\
\hline (2) Number of usability/UX problems identified & $\begin{array}{l}\text { P1 = Problems that are identified by both groups of } \\
\text { evaluators (common problems identified by both } \\
\text { groups) } \\
\text { P2 = Problems that are identified only by the group } \\
\text { that used the new set of heuristics (without } \\
\text { considering the common problems) } \\
\text { P3 = Problems that are identified only by the group } \\
\text { that used control heuristics (without considering the } \\
\text { common problems) }\end{array}$ \\
\hline $\begin{array}{l}\text { (3) Number of specific usability/UX problems } \\
\text { identified }\end{array}$ & 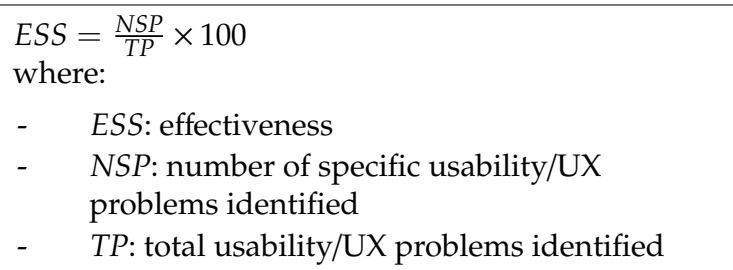 \\
\hline $\begin{array}{l}\text { (4) Number of identified usability/UX problems that } \\
\text { qualify as more severe (this is, how catastrophic the } \\
\text { usability/UX problem detected is) }\end{array}$ & $\begin{array}{l}E S V=\frac{N P V}{T P} \times 100 \\
\text { where: } \\
\text { - } \quad E S V: \text { effectiveness } \\
\text { - } \quad N P V: \text { number of usability/UX problems } \\
\quad \text { identified qualified with a severity greater } \\
\quad \text { than } 2 \\
\text { - } \quad T P: \text { total usability/UX problems identified }\end{array}$ \\
\hline $\begin{array}{l}\text { (5) Number of identified usability/UX problems that } \\
\text { qualify as more critical (this is, how severe and } \\
\text { frequent the problem detected is; understanding } \\
\text { frequency as the number of times a problem occurs. } \\
\text { Criticality is the sum of frequency and severity) }\end{array}$ & $\begin{array}{l}E S C=\frac{N P C}{T P} \times 100 \\
\text { where: } \\
\text { - } \quad \text { ESC: effectiveness } \\
\text { - } \quad \text { NPC: number of usability/UX problems } \\
\quad \text { identified qualified with a criticality greater } \\
\quad \text { than } 4 \\
\text { - } \quad \text { TP: total usability/UX problems identified }\end{array}$ \\
\hline
\end{tabular}


Table 3. Effectiveness of social network user experience heuristics, SNH (first iteration).

\begin{tabular}{|c|c|c|c|}
\hline & Experimental Group & Control Group & Observations \\
\hline Amount of evaluators & 3 & 3 & - \\
\hline Set of heuristics used & $\begin{array}{l}\text { Heuristics for social } \\
\text { networks (SNH) }\end{array}$ & Nielsen's heuristics (NH) & - \\
\hline Amount of heuristics (T) & 16 & 10 & - \\
\hline Total of problems identified (TP) & 42 & 34 & - \\
\hline $\begin{array}{c}\text { Number of specific problems } \\
\text { identified (NSP) }\end{array}$ & 17 & 9 & - \\
\hline $\begin{array}{l}\text { Number of problems identified } \\
\text { and qualified with a severity } \\
\text { greater than } 2 \text { (NPV) }\end{array}$ & 18 & 12 & - \\
\hline $\begin{array}{c}\text { Number of problems identified } \\
\text { and qualified with a criticality } \\
\text { greater than } 4 \text { (NPC) }\end{array}$ & 14 & 8 & - \\
\hline $\begin{array}{l}\text { Problems identified by both } \\
\text { groups (P1) }\end{array}$ & \multicolumn{2}{|c|}{12} & \multirow{3}{*}{$\begin{array}{l}\text { Given that (P1) and/or (P2) } \\
\text { include the highest amount of } \\
\text { problems, it is concluded that } \\
\text { SNH works better than NH }\end{array}$} \\
\hline $\begin{array}{l}\text { Problems identified by the } \\
\text { experimental group (P2) }\end{array}$ & 30 & - & \\
\hline $\begin{array}{l}\text { Problems identified by the } \\
\text { control group (P3) }\end{array}$ & - & 22 & \\
\hline $\begin{array}{l}\text { Total of the correct associations } \\
\text { ( }(\mathrm{CAHn})\end{array}$ & 32 & 18 & - \\
\hline $\begin{array}{c}\text { Total of the incorrect } \\
\text { associations ( } \sum \text { IAHn) }\end{array}$ & 10 & 16 & - \\
\hline $\begin{array}{l}\text { Percentage of the correct } \\
\text { associations (CA) }\end{array}$ & $\mathrm{CA} 1=76.19 \%$ & $\mathrm{CA} 2=52.9 \%$ & $\begin{array}{l}\text { Given that CA1 > CA2 it is } \\
\text { concluded that SNH works } \\
\text { better than NH (SNH has a } \\
\text { higher percentage of correct } \\
\text { associations) }\end{array}$ \\
\hline $\begin{array}{l}\text { Percentage of the incorrect } \\
\text { associations (IA) }\end{array}$ & $\mathrm{IA} 1=23.8 \%$ & IA $2=47.05 \%$ & $\begin{array}{l}\text { Given that IA1 < IA2 it is } \\
\text { concluded that SNH works } \\
\text { better than NH (SNH has a } \\
\text { lower percentage of correct } \\
\text { associations) }\end{array}$ \\
\hline $\begin{array}{l}\text { Effectiveness in terms of number } \\
\text { of specific problems identified } \\
\text { (ESS) }\end{array}$ & $\mathrm{ESS} 1=40.47 \%$ & $\mathrm{ESS} 2=26.47 \%$ & $\begin{array}{l}\text { Given that ESS1 > ESS2 it is } \\
\text { concluded that SNH works } \\
\text { better than NH (SNH finds } \\
\text { more specific usability/UX } \\
\text { problems than NH) }\end{array}$ \\
\hline $\begin{array}{l}\text { Effectiveness in terms of number } \\
\text { of problems identified and } \\
\text { qualified with a severity greater } \\
\text { than } 2 \text { (ESV) }\end{array}$ & $\mathrm{ESV} 1=42.85 \%$ & $\mathrm{ESV} 2=35.29 \%$ & $\begin{array}{l}\text { Given that ESV1 > ESV2 it is } \\
\text { concluded that SNH works } \\
\text { better than NH (SNH finds } \\
\text { that more usability/UX } \\
\text { problems qualify as more } \\
\text { severe than NH) }\end{array}$ \\
\hline $\begin{array}{l}\text { Effectiveness in terms of number } \\
\text { of problems identified and } \\
\text { qualified with a criticality } \\
\text { greater than } 4 \text { (ESC) }\end{array}$ & $\mathrm{ESC} 1=33.33 \%$ & $\mathrm{ESC} 2=23.52 \%$ & $\begin{array}{c}\text { Given that ESC1 > ESC2 it is } \\
\text { concluded that SNH works } \\
\text { better than NH (SNH finds } \\
\text { that more usability/UX } \\
\text { problems qualify as more } \\
\text { critical than NH) }\end{array}$ \\
\hline
\end{tabular}

\subsection{Second Iteration: Validation through Expert Judgment}

In the second iteration, we applied a survey to the three evaluators who used SNH set in the heuristic evaluation performed in the previous iteration. Specific scales have been proposed to validate the quality of heuristics $[4,39]$. We developed (and refined) our own scale to validate the quality of the heuristics through a survey $[6,39]$. The survey was designed to capture the evaluators' perception about 
SNWH set in four dimensions: D1—“Utility", D2-“Clarity", D3-“Ease of use", and D4-“Need of additional elements (checklists)". A five-point Likert scale was used (where 1 means "worst" and 5 means "best"). D4 has somehow an inverse scale. One would expect that if heuristic is perceived as useful, clear, and easy to use, then it does not need of additional elements. In addition, evaluators added comments for each heuristic.

Table 4 shows the average obtained for each dimension per heuristic. In general, heuristics obtained high grades (higher than 3.00). The dimension D1- “Utility" obtained the highest average (4.25), which means that heuristics are perceived as very useful for evaluating social networks. The dimension D4-“Need of additional elements (checklists)" obtained the lowest average (3.82); however, it is higher than the middle point (3.00). The above means the evaluators consider that it is necessary to add additional elements in the heuristics' specification to help in the detection of usability/UX problems; especially for SNWH7: "Minimize the user's memory load", SNWH12: "Privacy and exposure control", and SNWH13: "Content control published". The heuristics SNWH12 and SNWH13 are new and specific for evaluating social networks, so it is reasonable that evaluators consider it important to have additional elements to better understand the heuristics. On the other hand, the dimension D2- "Clarity" obtained an average of 3.88, which means that the heuristics' specification is not so clear; hence, the wording and explanations should be improved; especially for SNWH7: "Minimize the user's memory load" and SNWH9: "Aesthetic and minimalist design".

Table 4. Average perception scores for SNWH are set in the four evaluated dimensions (second iteration).

\begin{tabular}{|c|c|c|c|c|}
\hline Heuristic & D1-Utility & D2-Clarity & D3-Ease of Use & D4-N. of Add. Elem. \\
\hline $\begin{array}{l}\text { SNWH1: Visibility of } \\
\text { elements and system } \\
\text { status }\end{array}$ & 4.25 & 4.5 & 4.5 & 4 \\
\hline $\begin{array}{l}\text { SNWH2: Perception } \\
\text { and user status }\end{array}$ & 4.5 & 4.25 & 4.5 & 3.5 \\
\hline $\begin{array}{l}\text { SNWH3: Match } \\
\text { between system and } \\
\text { the real world }\end{array}$ & 4 & 3.25 & 3.25 & 3.75 \\
\hline $\begin{array}{l}\text { SNWH4: Consistency } \\
\text { and standards between } \\
\text { system elements }\end{array}$ & 4.5 & 4 & 4.25 & 3.5 \\
\hline $\begin{array}{l}\text { SNWH5: User control } \\
\text { and freedom }\end{array}$ & 4.5 & 4.5 & 4.25 & 3.5 \\
\hline $\begin{array}{l}\text { SNWH6: Error } \\
\text { prevention }\end{array}$ & 4.25 & 4 & 4 & 3.75 \\
\hline $\begin{array}{l}\text { SNWH7: Minimize the } \\
\text { user's memory load }\end{array}$ & 3.5 & 3 & 4 & 4.5 \\
\hline $\begin{array}{l}\text { SNWH8: Flexibility } \\
\text { and efficiency of use }\end{array}$ & 4 & 3.25 & 3.5 & 2.75 \\
\hline $\begin{array}{l}\text { SNWH9: Aesthetic } \\
\text { and minimalist design }\end{array}$ & 4 & 3 & 3.75 & 4 \\
\hline $\begin{array}{l}\text { SNWH10: Help user to } \\
\text { recognize, diagnose, } \\
\text { and recover from } \\
\text { errors }\end{array}$ & 4.5 & 4.25 & 4 & 3.25 \\
\hline $\begin{array}{l}\text { SNWH11: Help and } \\
\text { documentation }\end{array}$ & 4.5 & 4.5 & 4 & 3.5 \\
\hline $\begin{array}{l}\text { SNWH12: Privacy and } \\
\text { exposure control }\end{array}$ & 4.25 & 4.25 & 4 & 4.75 \\
\hline $\begin{array}{l}\text { SNWH13: Content } \\
\text { control published }\end{array}$ & 4.25 & 3.25 & 3.25 & 5 \\
\hline $\begin{array}{l}\text { SNWH14: Security and } \\
\text { recovery of user } \\
\text { account }\end{array}$ & 4.5 & 4.25 & 3.75 & 3.75 \\
\hline Average & 4.25 & 3.88 & 3.93 & 3.82 \\
\hline
\end{tabular}

\subsection{Third Iteration: Validation through User Tests and Expert Opinion}

In the third iteration, we performed a Co-discovery test to evaluate Facebook (in its 210-240 version). Co-discovery is a user testing method that offers valuable user thinking/thoughts insides [30]. Users explored Facebook in pairs, freely discussing it, while performing together predefined tasks. A total of eight users participated in the test forming four groups (two users per group). Participants 
were undergraduate students of 21-26 years old, from the Computer Science program at Pontificia Universidad Católica de Valparaíso (PUCV), Chile. All participants have experience using social networks and Facebook.

The experiment was designed to validate that the usability/UX problems identified in the heuristic evaluation (first iteration) are perceived as real problems for the users, and to identify new problems and review if these problems are evaluated by the SNXH set. The test was divided into three parts: (1) A pre-experiment questionnaire, aimed to broadly identify user's profile and his/her previous experience using Facebook; (2) a list of tasks to complete working in pairs (the experiment); and (3) a post-experiment satisfaction questionnaire, aimed to know the user's perception using Facebook.

We included questions concerning users' perceptions about task completion, orientation through the website, overall satisfaction regarding Facebook, and intention of future use. We also included open questions that allowed users to comment on Facebook's (perceived) positive and negative aspects. Table 5 shows the tasks performed by the users in the Co-discovery test and its results. The results of the questions asked were not included because the responses received were not significant to generate additional changes.

Based on the results, shown in Table 5, we concluded that the problems P1, P2, P3, P5, P6, and P10 are perceived as real problems for users since it was difficult for the groups complete the related tasks. We reviewed if SNXH allows evaluating the usability/UX problems detected in the test. As shown in Table 5, all problems detected in the Co-discovery test are covered by SNXH, except the problems P3 and P8, which means that it is necessary to create a new heuristic that evaluates the intuitive use of elements that do not confuse the user.

We also conducted an expert opinion for validating SNXH. We asked two experts in HCI what they think about the SNXH set. The experts had experience performing heuristic evaluations and using sets of usability/UX heuristics. They gave their points of view regarding whether the SNXH set is correctly specified, whether it is useful, what elements they would add or remove. Based on the feedback obtained, the SNXH set was refined. All the comments and recommendations were taken into account to improve the set. Experts said:

- Some heuristics refer to systems or websites, while others refer to applications. For consistency, it is recommended to use only one term (for example, "applications").

- SNXH5 (Prevention and recovery from errors) may cover many usability/UX problems. Prevent errors is not the same that recover from them. SNXH5 should be separated into two heuristics.

- The name of some heuristics may confuse the evaluator, since it does not make clear what aspects it evaluates. For example, the name "Design and interface" (SNXH2) does not make clear if what is evaluated with the heuristic is the interface aesthetic part ("design"), or the interface type and its elements ("interface"). On the other hand, for the SNXH9 (Privacy and exposure control), it is not clear what is "exposure control". The heuristic description is related to privacy. It is recommended to simplify the heuristic name so that it is clearer what aspect it evaluates.

- SNXH12 (Consistency between platforms) specification implies that the heuristic evaluates aspects related to standards in different platforms, but its name does not indicate it.

- SNXH8 (Alert and notification control) is too specific. The heuristic is oriented to evaluate only notifications and alerts, so it is very likely that it has few (or no) associated usability/UX problems. It is recommended to modify the heuristic to evaluate more aspects that can be customizable (such as messages, sounds, etc.).

- The explanation of SNXH10 (security and recovery of user account) does not cover the "recovery of user account" aspect. The explanation should be improved to be consistent with the heuristic name.

- There is no heuristic that evaluates the flexibility of use. This is a critical element in social networks, since users use them in different contexts to meet different objectives. In addition, users may (or may not) have experience using similar social networks, so they should be tolerable at different levels of user experience. 
Table 5. Co-discovery test quantitative results (third iteration).

\begin{tabular}{|c|c|c|c|c|}
\hline Task (T) & $\begin{array}{c}\text { Usability/UX Problems } \\
\text { Related (P) }\end{array}$ & $\begin{array}{l}\text { Percentage of Task } \\
\text { Fulfillment }\end{array}$ & Description & $\begin{array}{l}\text { Heuristic Related } \\
\text { (Third Iteration } \\
\text { Version, SNXH) }\end{array}$ \\
\hline $\begin{array}{l}\text { T1: Search for the } \\
\text { "event" word in the } \\
\text { quick help section }\end{array}$ & $\begin{array}{l}\text { - } \quad \text { 1: The quick help } \\
\text { section is hard to find. } \\
\text { - } 2 \text { 2: It is not possible to } \\
\text { search for help } \\
\text { through the main } \\
\text { search engine. }\end{array}$ & $\begin{array}{l}75 \% \\
\text { (3 of } 4 \text { groups) }\end{array}$ & $\begin{array}{l}\text { Although for three } \\
\text { groups, it was difficult } \\
\text { to find the quick help } \\
\text { section, after several } \\
\text { attempts, they were } \\
\text { able to locate the } \\
\text { section and complete } \\
\text { the task. } \\
1 \text { group could not } \\
\text { complete the task since } \\
\text { they used the main } \\
\text { website search engine, } \\
\text { which did not show } \\
\text { the information they } \\
\text { were looking for. }\end{array}$ & 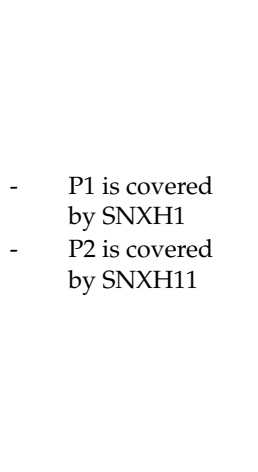 \\
\hline $\begin{array}{l}\text { T2: Create an event } \\
\text { by adding name, } \\
\text { location, date, time, } \\
\text { and description }\end{array}$ & $\begin{array}{l}\text { P3: The creation of } \\
\text { events is confusing. } \\
\text { - P4: The website does } \\
\text { not indicate what } \\
\text { information } \\
\text { is required. }\end{array}$ & $\begin{array}{l}100 \% \\
\text { (4 of } 4 \text { groups) }\end{array}$ & $\begin{array}{l}\text { - } \\
\text { correctly groups were able to } \\
\text { the task. } \\
\text { - } \quad \text { For a group, the } \\
\text { creation of the event } \\
\text { was complicated, but } \\
\text { then they understood } \\
\text { how to use } \\
\text { the functionality. }\end{array}$ & $\begin{array}{l}\text { P3 is not covered } \\
\text { by SNXH } \\
\text { P4 is covered } \\
\text { by SNXH5 }\end{array}$ \\
\hline $\begin{array}{l}\text { T3: Invite three } \\
\text { friends to the event }\end{array}$ & $\begin{array}{l}\text { P5: The option to add } \\
\text { more guests to an } \\
\text { event (apart from } \\
\text { friends) is hard to find } \\
\text { and use. } \\
\text { - P6: Additional options } \\
\text { for events are hard } \\
\text { to find. }\end{array}$ & $\begin{array}{l}50 \% \\
\text { (2 of } 4 \text { groups) }\end{array}$ & $\begin{array}{l}2 \text { groups could not } \\
\text { complete the task, } \\
\text { since they did not find } \\
\text { the option to invite } \\
\text { additional friends. } \\
\text { It was difficult for one } \\
\text { group to understand } \\
\text { how to invite } \\
\text { additional friends, but } \\
\text { after a couple of tries, } \\
\text { they were able to } \\
\text { complete the task. }\end{array}$ & $\begin{array}{l}\text { P5 is covered } \\
\text { by SNXH5 } \\
\text { P6 is covered } \\
\text { by SNXH1 }\end{array}$ \\
\hline $\begin{array}{l}\text { T4: Create a } \\
\text { publication in the } \\
\text { event and associate } \\
\text { a sentiment with } \\
\text { the publication }\end{array}$ & 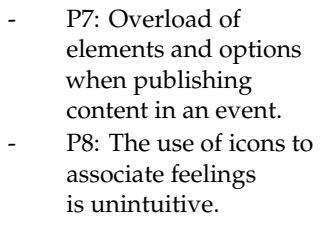 & $\begin{array}{l}100 \% \\
\text { (4 of } 4 \text { groups) }\end{array}$ & $\begin{array}{l}\text { All groups were able to } \\
\text { correctly perform } \\
\text { the task. }\end{array}$ & $\begin{array}{l}\text { P7 is covered } \\
\text { by SNXH4 } \\
\text { P8 is not covered } \\
\text { by SNXH }\end{array}$ \\
\hline $\begin{array}{l}\text { T5: Delete the } \\
\text { created event }\end{array}$ & $\begin{array}{l}\text { P9: Limited options to } \\
\text { remove information. } \\
\text { P10: The option to } \\
\text { eliminate an event is } \\
\text { difficult to find (option } \\
\text { not visible). }\end{array}$ & $\begin{array}{l}100 \% \\
\text { (4 of } 4 \text { groups) }\end{array}$ & $\begin{array}{l}\text { - All groups were able to } \\
\text { correctly perform } \\
\text { the task. } \\
\text { Although all groups to } \\
\text { completed the task, it } \\
\text { was difficult to find the } \\
\text { option to delete the } \\
\text { event, since this } \\
\text { functionality is not } \\
\text { clearly visible in } \\
\text { the interface. }\end{array}$ & $\begin{array}{l}\text { P9 is covered } \\
\text { by SNXH6 } \\
\text { P10 is covered } \\
\text { by SNXH1 }\end{array}$ \\
\hline
\end{tabular}




\section{SNUXH: A Set of Social Network User Experience Heuristics}

Based on the iterations and validations described in the previous sections, the SNUXH set was refined and improved.

We develop 14 heuristics. Of these, four are considered critical (with priority 3: SNUXH3, SNUXH12, SNUXH13, and SNUXH14), because they evaluate specific and crucial aspects of social networks; seven heuristics are considered important (with priority 2: SNUXH2, SNUXH4, SNUXH5, SNUXH6, SNUXH7, SNUXH9, and SNUXH11), since they evaluate relevant aspects of social networks; and three heuristics are considered useful (with priority 1: SNUXH1, SNUXH8, and SNUXH10), since they evaluate elements that improve the UX. Regarding usability attributes: Six heuristics evaluate effectiveness, six heuristics evaluate efficiency, and nine heuristics evaluate the satisfaction. Regarding the UX attributes: Two heuristics evaluate the useful factor, nine the usable factor, six the desirable factor, five the findable factor, and seven the credible factor.

Of all the proposed heuristics, SNUXH12 is a brand-new heuristic created to evaluate specific features of social networks. It focuses on evaluating customization, content management, and interaction with a social network regarding the published content that users want (or do not want) to see. Users should feel comfortable and confident when browsing a social network, so they should have options to configure what they want to see.

The 14 heuristics are presented below. Each heuristic is presented as a table that includes 13 elements (Tables 6-19): id; priority (how important the heuristic is: useful, important or critical); name; definition; explanation; social network feature (feature(s) evaluated with the heuristic); examples (examples with images of compliance with the heuristic); benefits (expected usability/UX benefits when the heuristic is satisfied); problems (anticipated problems of confusing heuristics and misunderstanding); checklist; usability attribute related (attribute evaluated with the heuristic); UX attribute related (attribute evaluated with the heuristic); and set(s) of existing heuristics related (set on which the heuristic is based, if exist, and the heuristic that evaluates to some degree a certain general feature or a specific feature of social networks).

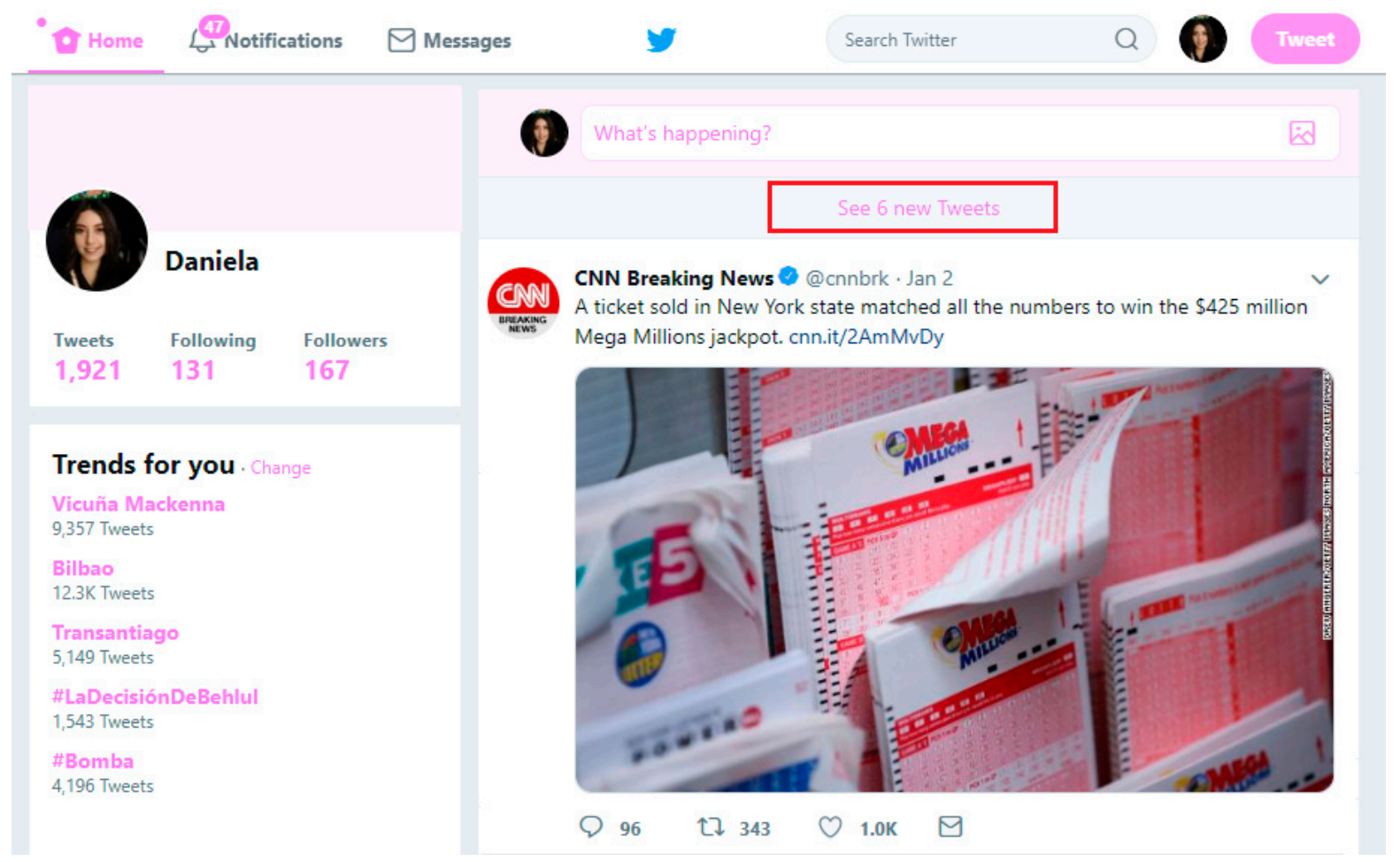

Figure 2. SNUXH1: Visual feedback and social network status. 
Table 6. SNUXH1: Visual feedback and social network status.

\begin{tabular}{cl}
\hline Id & SNUXH1 \\
\hline Name & Visual Feedback and Social Network Status \\
\hline Priority & (1) Useful \\
\hline Definition & $\begin{array}{l}\text { The social network must inform the user application's status in response to } \\
\text { the actions that he/she performs. }\end{array}$ \\
\hline The social network must inform the user through feedback (such as visual \\
or auditory feedback), the state of the application, and the events that occur \\
while the user interacts with it. The social network must inform the user \\
when the application waits for an action from him/her.
\end{tabular}

1. The social network offers loading elements that inform users of the state of processes that he/she performs (e.g., loading bars).

2. The user must be able to visualize the content loaded to the social network (videos, images, texts) through a representative visual element, especially when the files to upload will take longer than expected.

Checklist 3. The social network indicates if a process is taking longer than expected.

4. The social network executes the functionality expected by the user when performing an action.

5. The social network communicates to the user the number of new publications.

6. The social network is updated in real-time (when it applies).

\begin{tabular}{cl}
\hline Usability attribute related & Satisfaction, Efficiency \\
\hline UX attribute related & Usable, Findable \\
\hline \multirow{3}{*}{ Sets of heuristics related } & Nielsen, "Visibility of system status" [10] \\
& Esteves et al., "Privacy and exhibition control” [13] \\
& Yeratziotis et al., "Visibility", "Availability" [14] \\
\hline
\end{tabular}




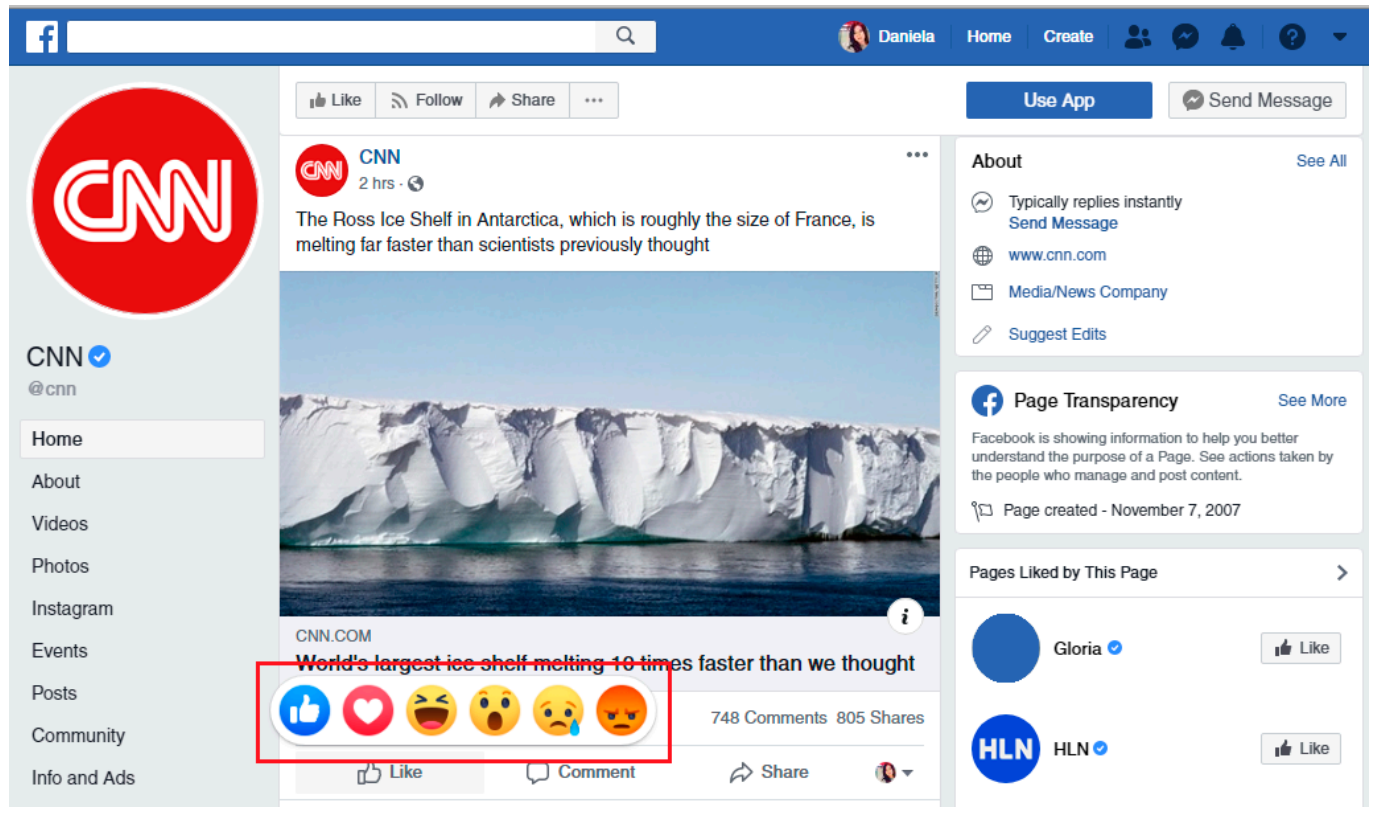

Figure 3. SNUXH2: Match between the social network and real world.

Table 7. SNUXH2: Match between the social network and real world.

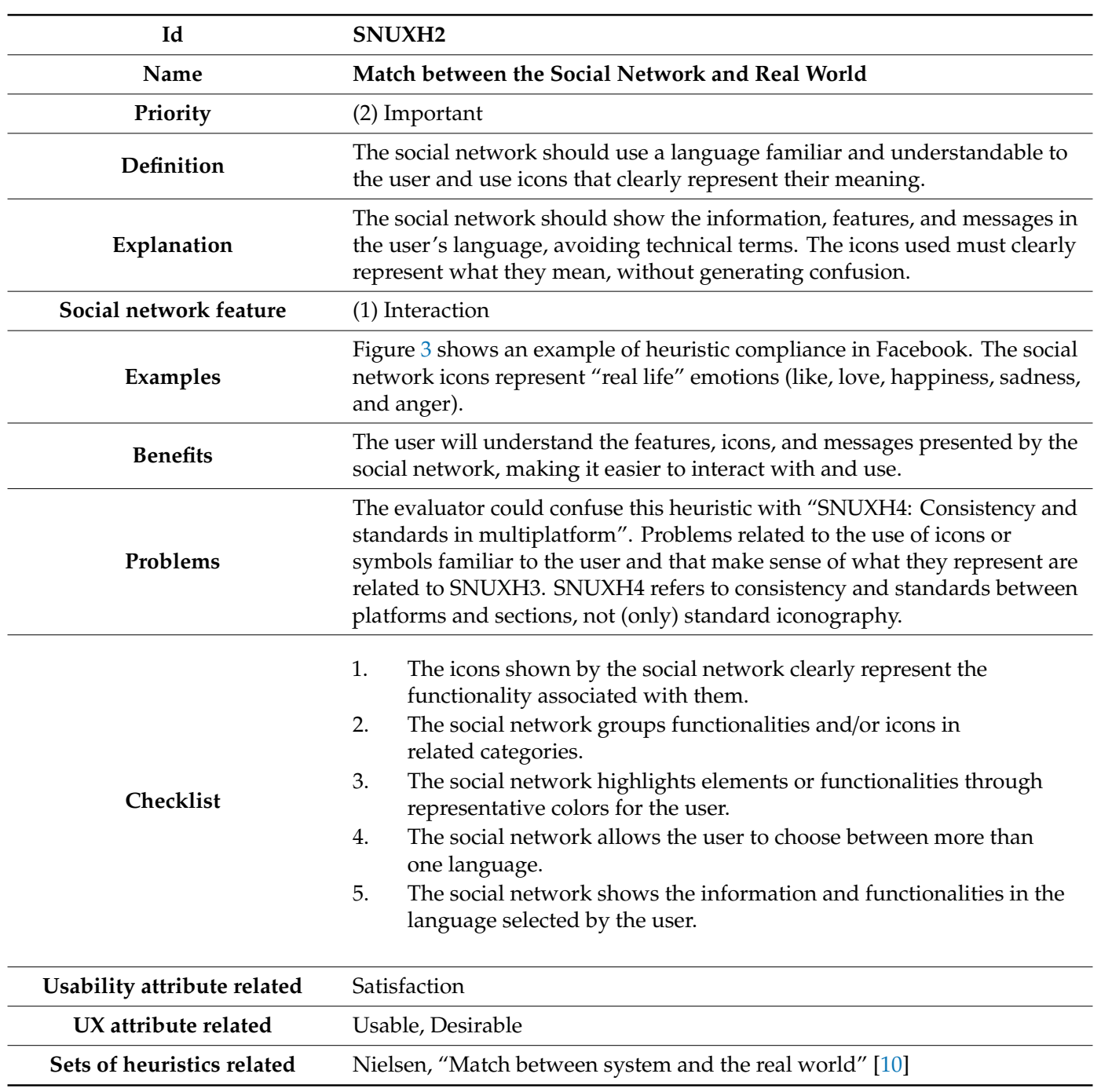




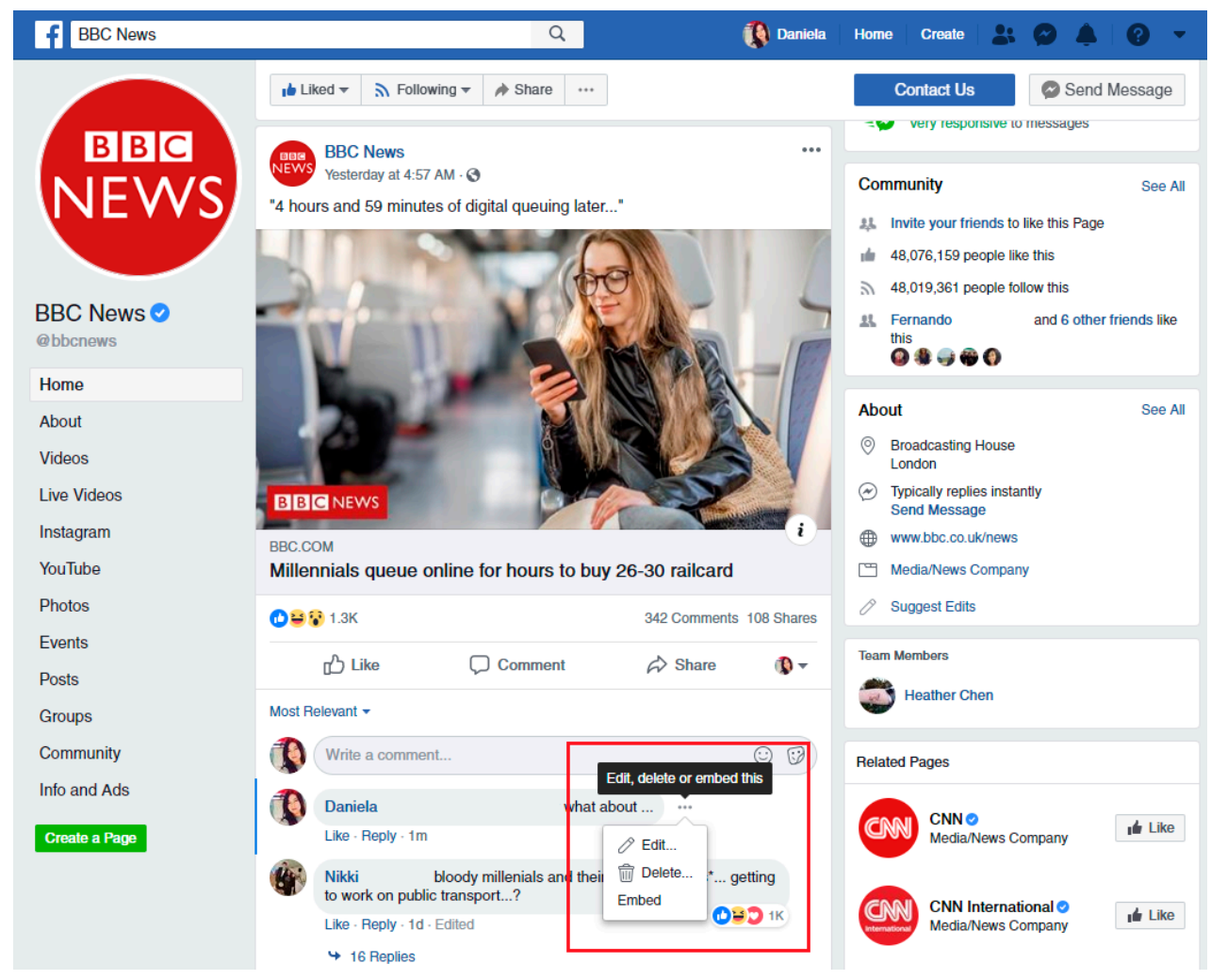

Figure 4. SNUXH3: User control and freedom.

Table 8. SNUXH3: User control and freedom.

\begin{tabular}{|c|c|}
\hline Id & SNUXH3 \\
\hline Name & User Control and Freedom \\
\hline Priority & (3) Critical \\
\hline Definition & $\begin{array}{l}\text { The user must feel that he/she manages the social network, being able to undo or redo his/her } \\
\text { actions and use the social network freely. }\end{array}$ \\
\hline Explanation & $\begin{array}{l}\text { The social network must allow the user to control the actions performed, providing options, } \\
\text { such as go back, go to home, cancel, confirm (among others). The user must be able to freely use } \\
\text { the functionalities of the social network without fear of permanent errors. }\end{array}$ \\
\hline Social network feature & (1) Content management, (2) Interaction \\
\hline Examples & $\begin{array}{l}\text { Figure } 4 \text { shows an example of heuristic compliance in Facebook. The social network allows } \\
\text { actions to edit and/or delete the comment. }\end{array}$ \\
\hline Benefits & Social networks that allow controlling actions make users feel comfortable and confident. \\
\hline Problems & $\begin{array}{l}\text { This heuristic should not be confused with the concept of flexibility and customization } \\
\text { (SNUXH8). SNUXH3 refers to the control that the user has on the actions performed and the } \\
\text { freedom to manage them (such as "undo" actions), while SNUXH8 refers to the social network } \\
\text { allows the user to adapt their elements easily according to his/her needs. }\end{array}$ \\
\hline Checklist & $\begin{array}{l}\text { 1. The social network allows us to always return to the homepage (through its main logo). } \\
\text { 2. The social network does not publish content that the user has not previously authorized. } \\
\text { 3. The social network must provide options to undo and redo actions. } \\
\text { 4. The social network must allow the user to cancel options selected by mistake. } \\
\text { 5. The social network must include options to go back, edit or delete publications or } \\
\text { comments made by the user. }\end{array}$ \\
\hline Usability attribute related & Satisfaction, Effectiveness \\
\hline UX attribute related & Usable, Credible \\
\hline Set of heuristics related & $\begin{array}{l}\text { Nielsen, "User control and freedom" [10] } \\
\text { Yeratziotis et al., "Revocability" [14] }\end{array}$ \\
\hline
\end{tabular}



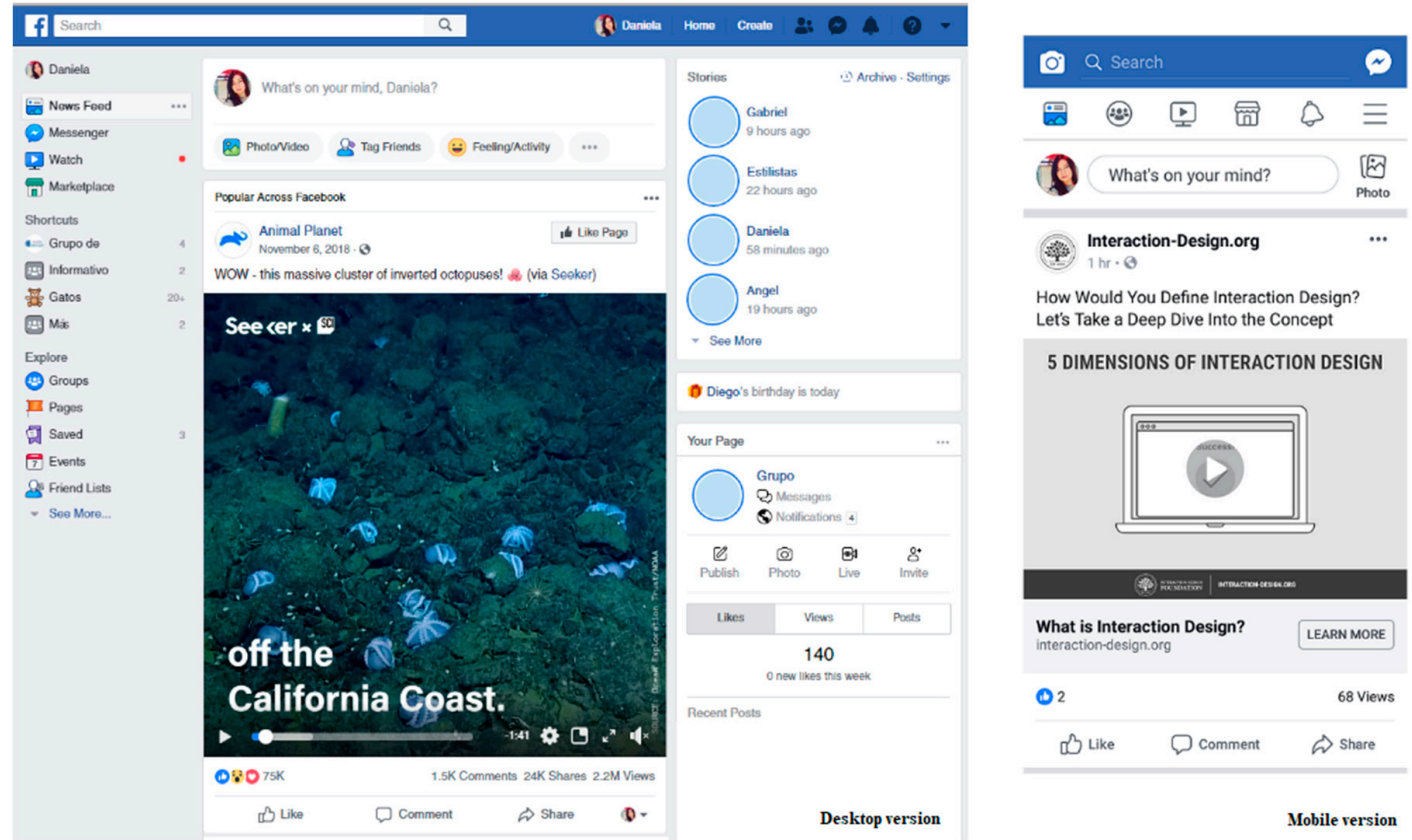

Figure 5. SNUXH4: Consistency and standards in multiplatform.

Table 9. SNUXH4: Consistency and standards in multiplatform.

\begin{tabular}{|c|c|}
\hline Id & SNUXH4 \\
\hline Name & Consistency and Standards in Multiplatform \\
\hline Priority & (2) Important \\
\hline Definition & $\begin{array}{l}\text { The social network must be consistent in the several platforms that support it. The same } \\
\text { functionalities must be present, there should not be differences (e.g., visual differences, behavior } \\
\text { differences, etc.), and the standards must be followed for each platform. }\end{array}$ \\
\hline Explanation & $\begin{array}{l}\text { Several social network platforms (for example, desktop and mobile version) must present } \\
\text { elements and actions that have the same meaning. The design, standards, and functionalities } \\
\text { must be maintained along with the platforms to not alter the user interaction. }\end{array}$ \\
\hline Social network feature & (1) Customization, (2) Connectivity, (3) Content management, and (4) Interaction \\
\hline Examples & $\begin{array}{l}\text { Figure } 5 \text { shows the consistency between the desktop and mobile versions of Facebook. The } \\
\text { colors, icons (some), and type of letter are consistent on both platforms. However, while some } \\
\text { features are maintained on both platforms (such as "Search" and "What's on your mind?"), } \\
\text { others change and are only present in the mobile version (the icon to take photos, located in the } \\
\text { upper left corner of the screen, where usually the logo of the social network is located). }\end{array}$ \\
\hline Benefits & $\begin{array}{l}\text { The user will easily interpret the representative elements (icons) used in the social network, } \\
\text { facilitating the use of the available functionalities, and helping their learning process. }\end{array}$ \\
\hline Problems & $\begin{array}{l}\text { The evaluator may confuse the concept of consistency (SNUXH4) with aesthetics (SNUXH7 } \\
\text { "Aesthetic and minimalist design"). Consistency refers to the fact that there must be coherence } \\
\text { between the elements of the social network, while aesthetics refers to combining (interface) } \\
\text { elements that together generate a visually pleasing appearance. }\end{array}$ \\
\hline Checklist & $\begin{array}{l}\text { 1. The social network uses the same kind of symbols to show information and actions in the } \\
\text { different sections and/or platforms. } \\
\text { 2. The social network has the same content distribution in different sections and/or platforms. } \\
\text { 3. The social network presents the same functionalities in the different sections } \\
\text { and/or platforms. } \\
\text { 4. The social network presents the same colors in the different sections and/or platforms. } \\
\text { 5. The social network presents the same type of letter in the different sections } \\
\text { and/or platforms. }\end{array}$ \\
\hline Usability attribute related & Effectiveness, Efficiency \\
\hline UX attribute related & Usable, Findable \\
\hline Set of heuristics related & $\begin{array}{l}\text { Nielsen, "Consistency and standards" [10] } \\
\text { Esteves et al., "Uniform interface" [13] }\end{array}$ \\
\hline
\end{tabular}




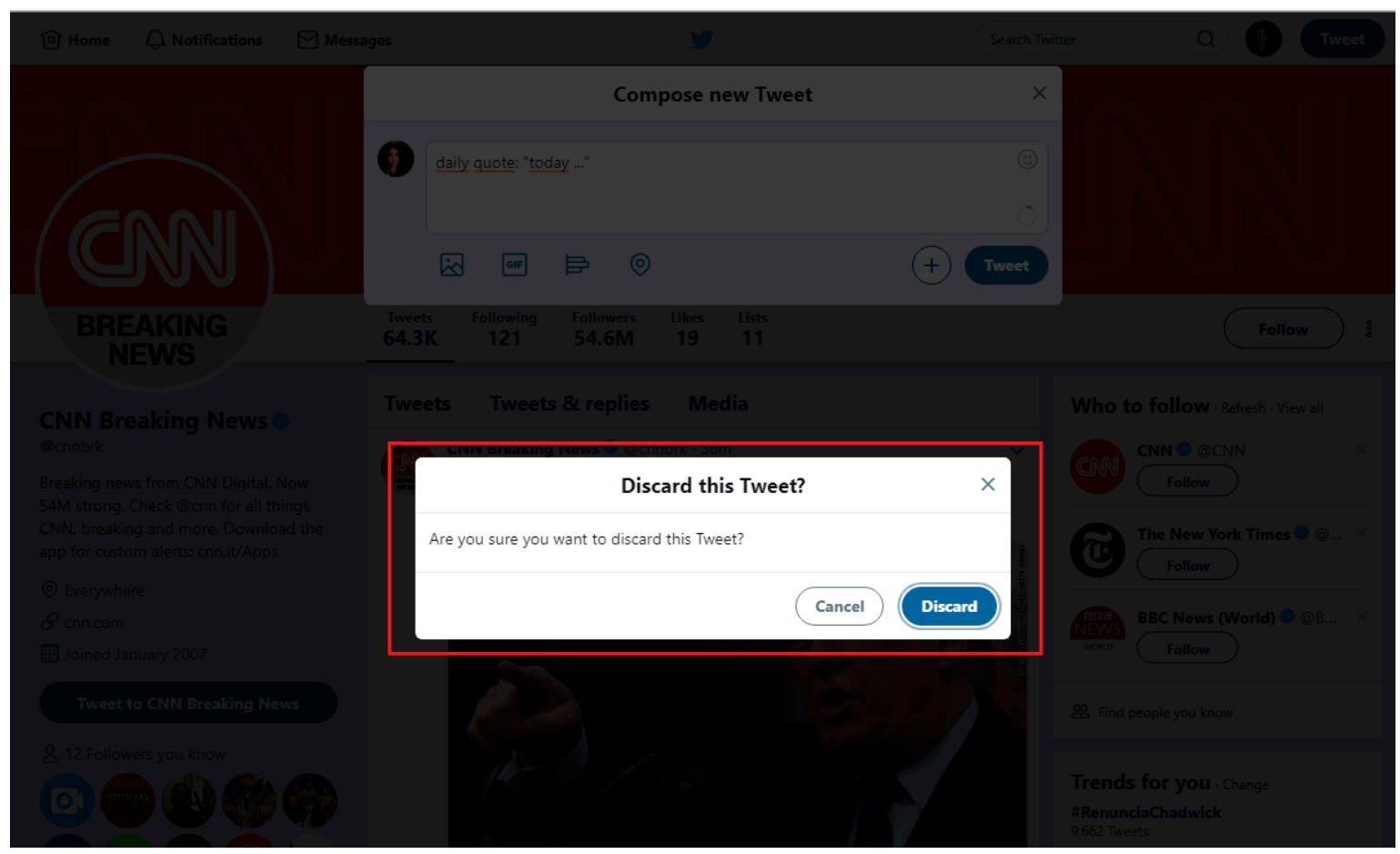

Figure 6. SNUXH5: Error prevention.

Table 10. SNUXH5: Error prevention.

\begin{tabular}{|c|c|}
\hline Id & SNUXH5 \\
\hline Priority & (2) Important \\
\hline Definition & $\begin{array}{l}\text { The social network must prevent errors from occurring, providing warning messages to the user } \\
\text { with useful information and without technical terms. }\end{array}$ \\
\hline Explanation & $\begin{array}{l}\text { The social network must prevent errors and warn the user before performing an action that leads } \\
\text { to unwanted situations or status. The social network should not make available to the user } \\
\text { functionalities that are not yet operational. }\end{array}$ \\
\hline Social network feature & (1) Security, (2) Connectivity, (3) Interaction, and (4) Help center \\
\hline Examples & $\begin{array}{l}\text { Figure } 6 \text { shows an example of heuristic compliance in Twitter. The social network displays a } \\
\text { warning message to the user, asking if he/she is sure to discard the tweet to publish. }\end{array}$ \\
\hline Benefits & $\begin{array}{l}\text { Social networks that prevent errors and that do not publish unwanted content make the user } \\
\text { interaction more effective, avoiding user frustrations. }\end{array}$ \\
\hline Checklist & $\begin{array}{l}\text { 1. The social network prevents errors from occurring by displaying warning messages to } \\
\text { the user. } \\
\text { 2. The social network informs the user that the action he/she is doing will be canceled before } \\
\text { changing the section. } \\
\text { 3. The social network clearly indicates which fields are mandatory for the continuation of } \\
\text { any process. } \\
\text { 4. The social network presents its functionalities and icons with adequate separation between } \\
\text { them, to prevent the user from pressing the wrong element. }\end{array}$ \\
\hline
\end{tabular}




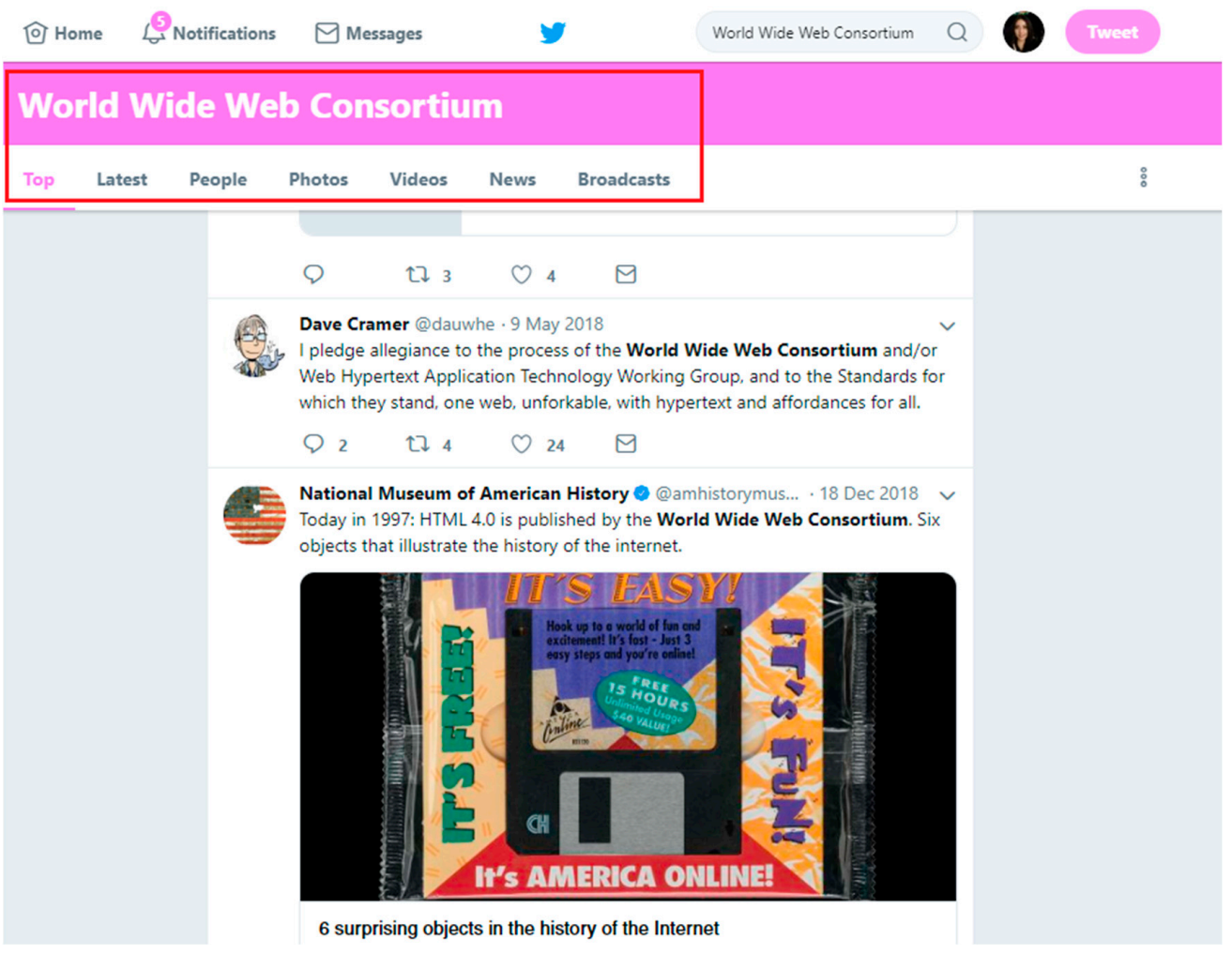

Figure 7. SNUXH6: Minimize the user's memory load.

Table 11. SNUXH6: Minimize the user's memory load.

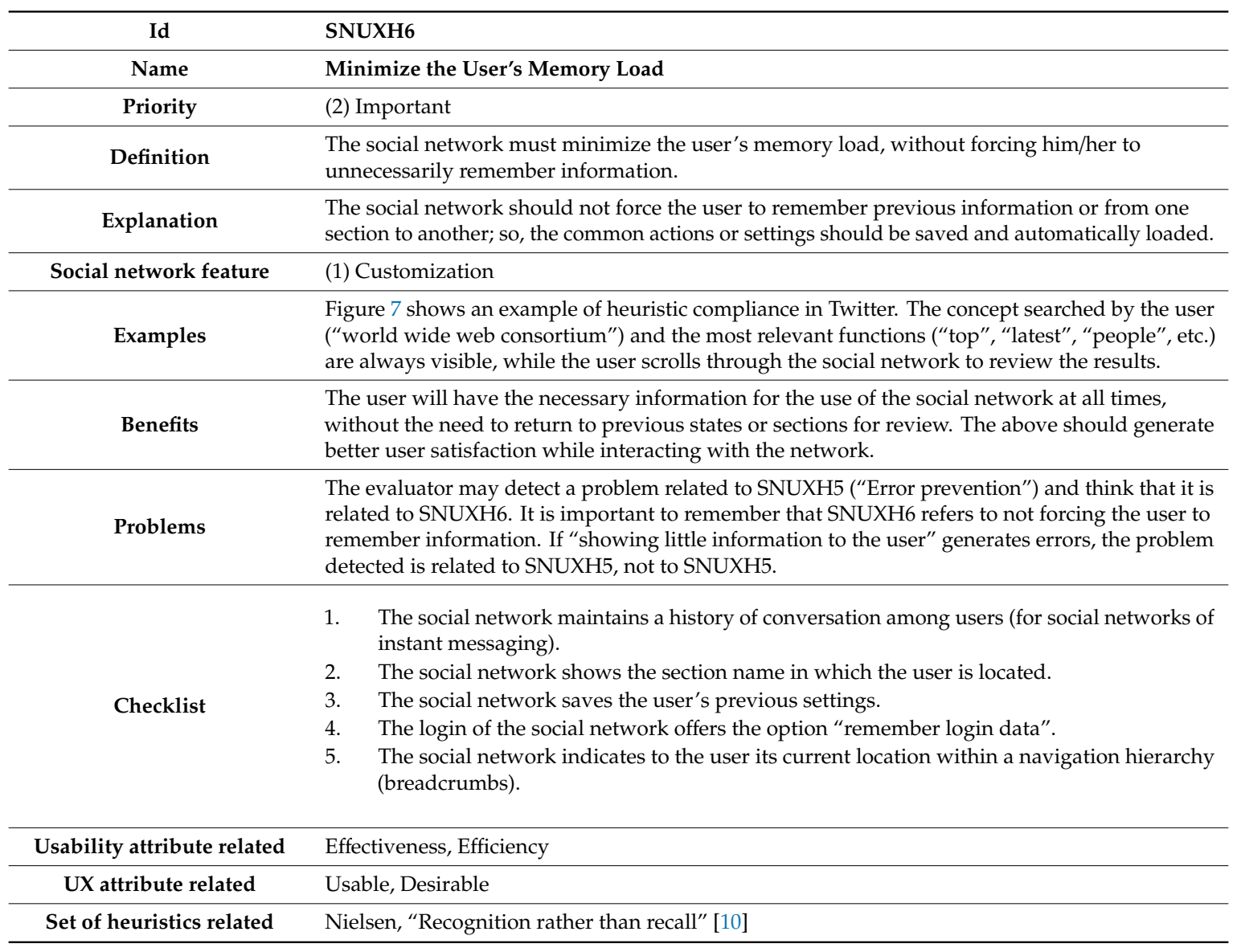




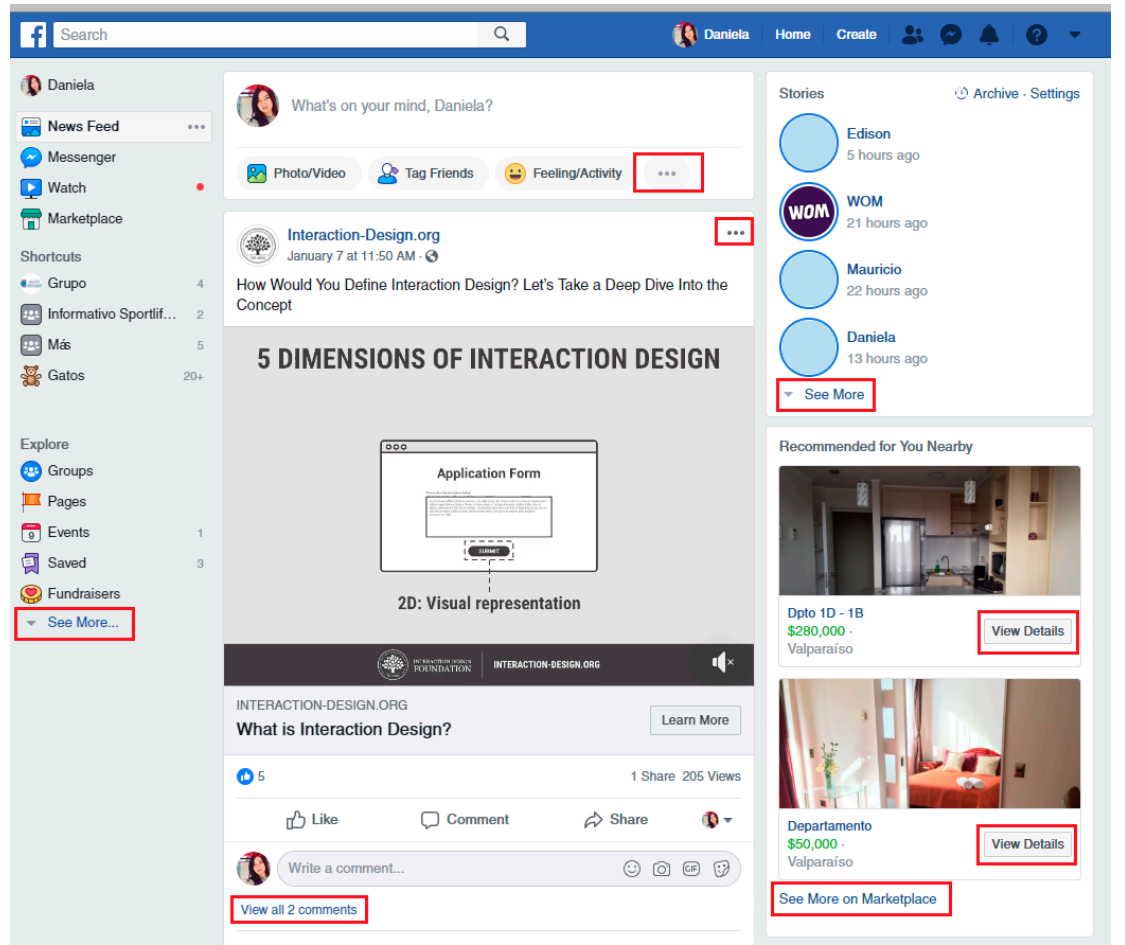

Figure 8. SNUXH7: Aesthetic and minimalist design.

Table 12. SNUXH7: Aesthetic and minimalist design.

\begin{tabular}{|c|c|}
\hline Id & SNUXH7 \\
\hline Priority & (2) Important \\
\hline Explanation & $\begin{array}{l}\text { The main functionalities of the social network (such as publishing content and comment) must be } \\
\text { differentiated from each other, hiding less usual options that may distract the user. The social network } \\
\text { should show information according to the user preferences, hiding information that he/she has not } \\
\text { decided to visualize. }\end{array}$ \\
\hline Social network feature & (1) Interaction \\
\hline Examples & $\begin{array}{l}\text { Figure } 8 \text { shows an example of heuristic compliance in Facebook. The most relevant options and } \\
\text { information are displayed, providing options to the user to see more details of the publications or } \\
\text { comments (e.g., "view all comments", "view details") and to access to more functions or sections (e.g., } \\
\text { "see more", additional option menu " } 3 \text { dots"). }\end{array}$ \\
\hline Problems & $\begin{array}{l}\text { The evaluator may confuse SNUXH7 with SNUXH6 ("Minimize the user's memory load"). SNUXH7 } \\
\text { refers to maintain a "clean" interface, showing only the relevant elements of the social network to the user. } \\
\text { If the problem of showing few information forces the user to have to remember elements, the problem is } \\
\text { related to SNUXH6, not to SNUXH7. }\end{array}$ \\
\hline Checklist & $\begin{array}{l}\text { 1. The social network shows important information for the user, highlighting it properly without } \\
\text { disturbing visually. } \\
\text { 2. The social network highlights the publications most commented by users. } \\
\text { 3. The social network appropriately uses the different sizes and types of letters depending on the } \\
\text { importance of the information. } \\
\text { 4. The social network separates the information making good use of the space. } \\
\text { 6. The social network avoids information not relevant to the user (e.g., in "Home" or "Timeline"). } \\
\text { them from the restless relevant. }\end{array}$ \\
\hline
\end{tabular}




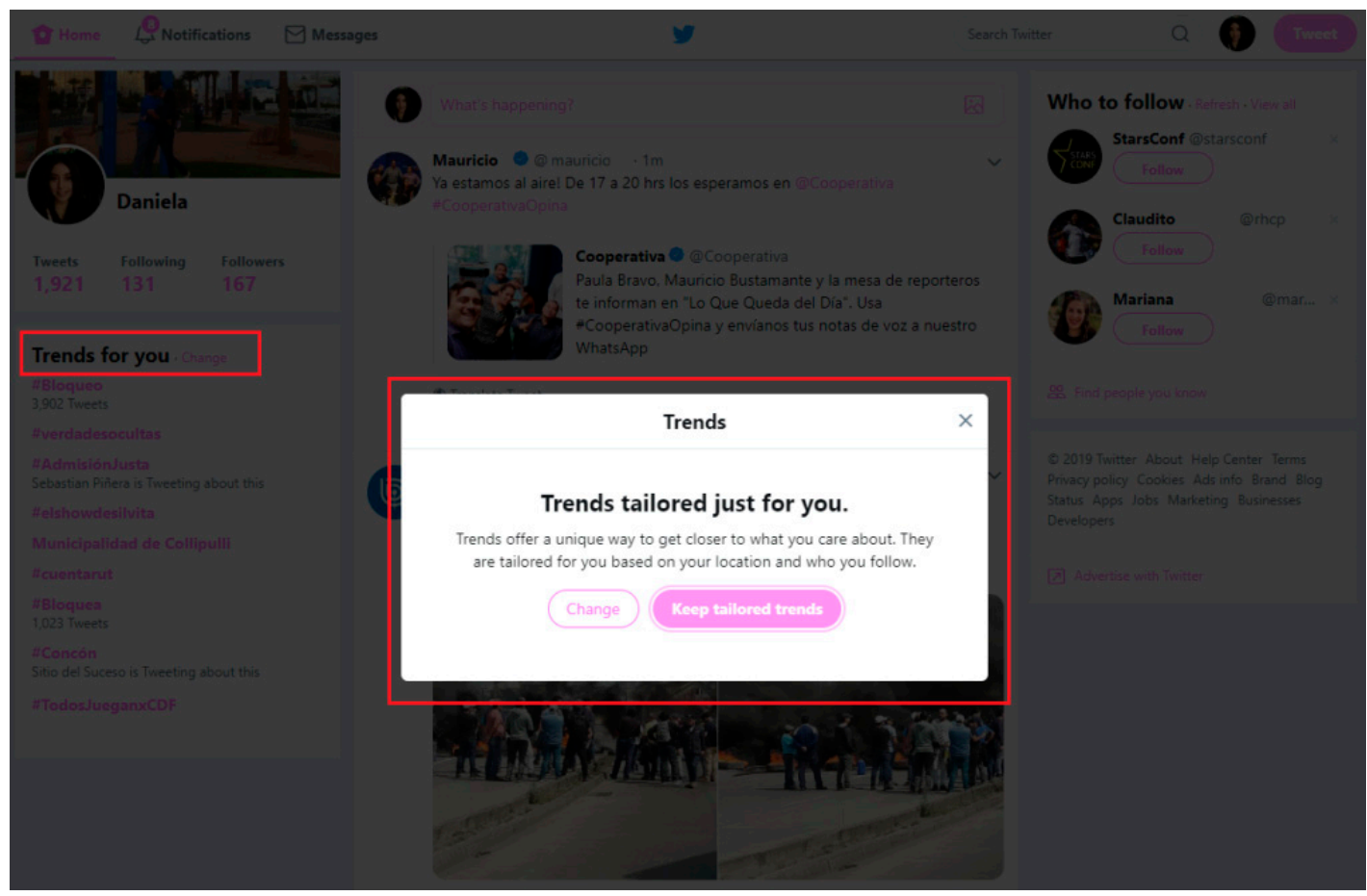

Figure 9. SNUXH8: Flexibility and customization.

Table 13. SNUXH8: Flexibility and customization.

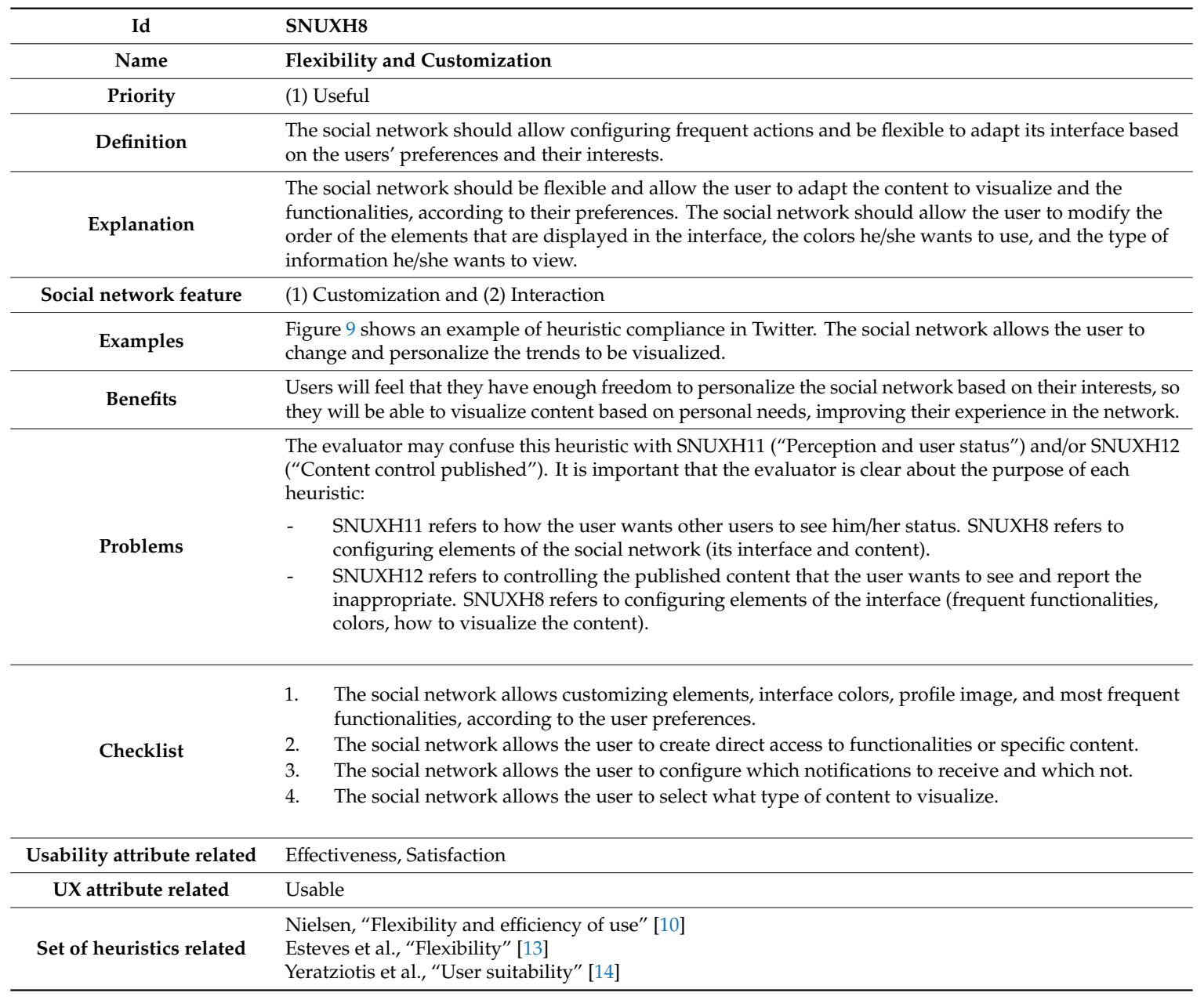




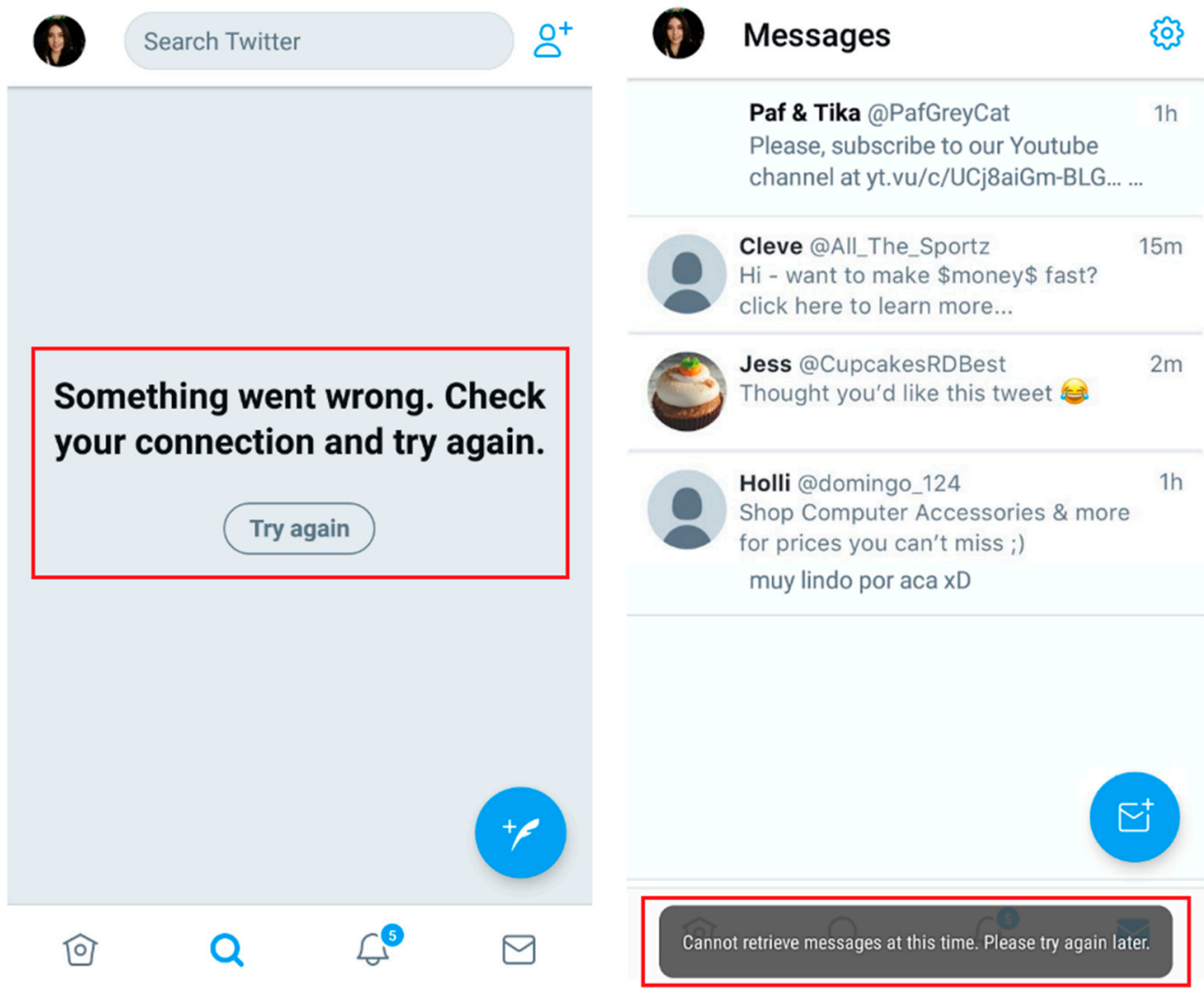

Figure 10. SNUXH9: Help users recognize, diagnose, and recover from errors.

Table 14. SNUXH9: Help users recognize, diagnose, and recover from errors.

\begin{tabular}{|c|c|}
\hline Id & SNUXH9 \\
\hline Priority & (2) Important \\
\hline Explanation & $\begin{array}{l}\text { When an error occurs, the social network must indicate the problem occurred through error messages } \\
\text { expressed in an understandable language. The messages should accurately indicate the problem and } \\
\text { suggest a constructive solution. }\end{array}$ \\
\hline Social network feature & (1) Security, and (2) Help center \\
\hline Examples & $\begin{array}{l}\text { Figure } 10 \text { shows an example of heuristic compliance in Twitter. The social network displays error } \\
\text { messages indicating that a problem has occurred ("something went wrong", "cannot retrieve } \\
\text { messages"), its possible reason ("connection problems"), and solution ("please try again"). }\end{array}$ \\
\hline Benefits & Social networks that guide the user to solve problems easily and quickly generate better experience. \\
\hline Checklist & $\begin{array}{l}\text { 1. The social network immediately informs the user if he/she made a mistake when completing a } \\
\text { field (e.g., "username" or "password" field). } \\
\text { 2. Error messages displayed by the social network are written in a simple and easy to understand } \\
\text { language for users. } \\
\text { 3. Error messages include the reason why a problem occurred and its possible solution. } \\
\text { 4. The social network informs the user on how to leave the unwanted situation in which he/she is. }\end{array}$ \\
\hline Usability attribute related & Efficiency \\
\hline UX attribute related & Useful, Credible \\
\hline Set of heuristics related & $\begin{array}{l}\text { Nielsen, "Help users recognize, diagnose, and recover from errors" [10] } \\
\text { Yeratziotis et al., "Errors" [14] }\end{array}$ \\
\hline
\end{tabular}




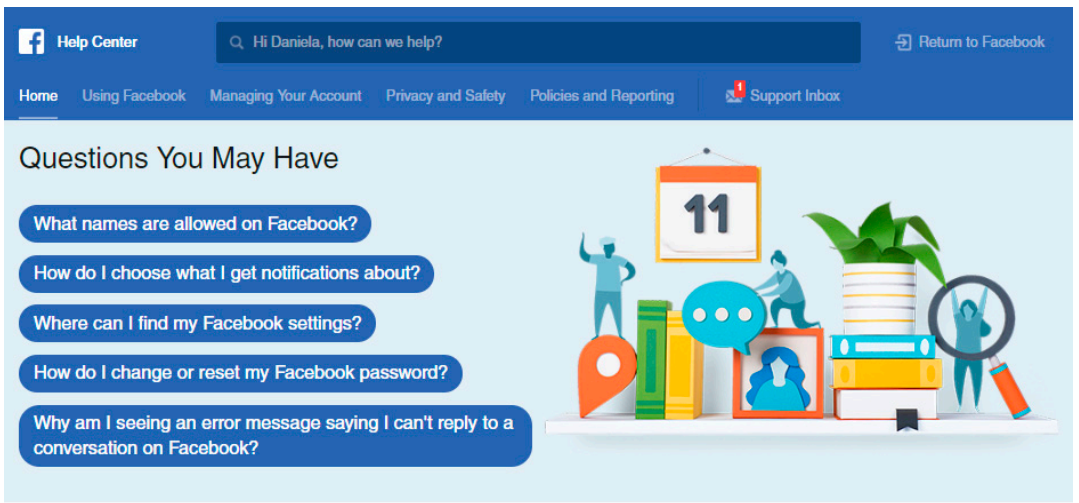

Popular Topics

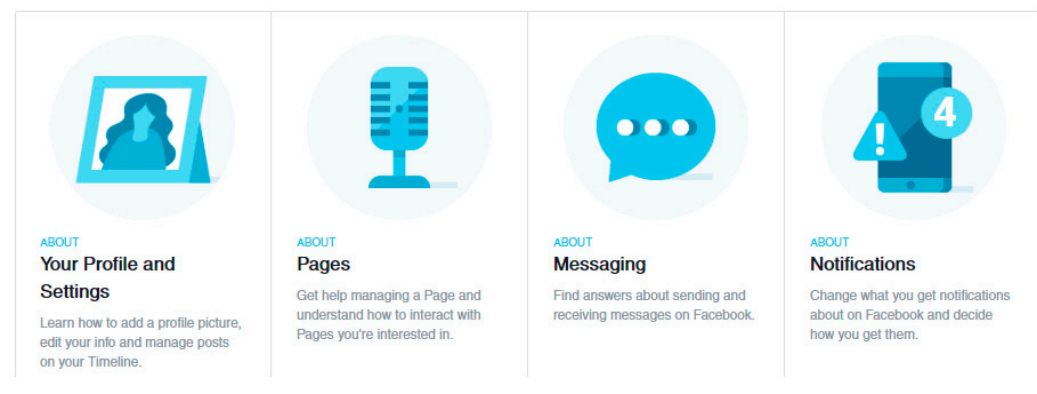

Figure 11. SNUXH10: Help center.

Table 15. SNUXH10: Help center.

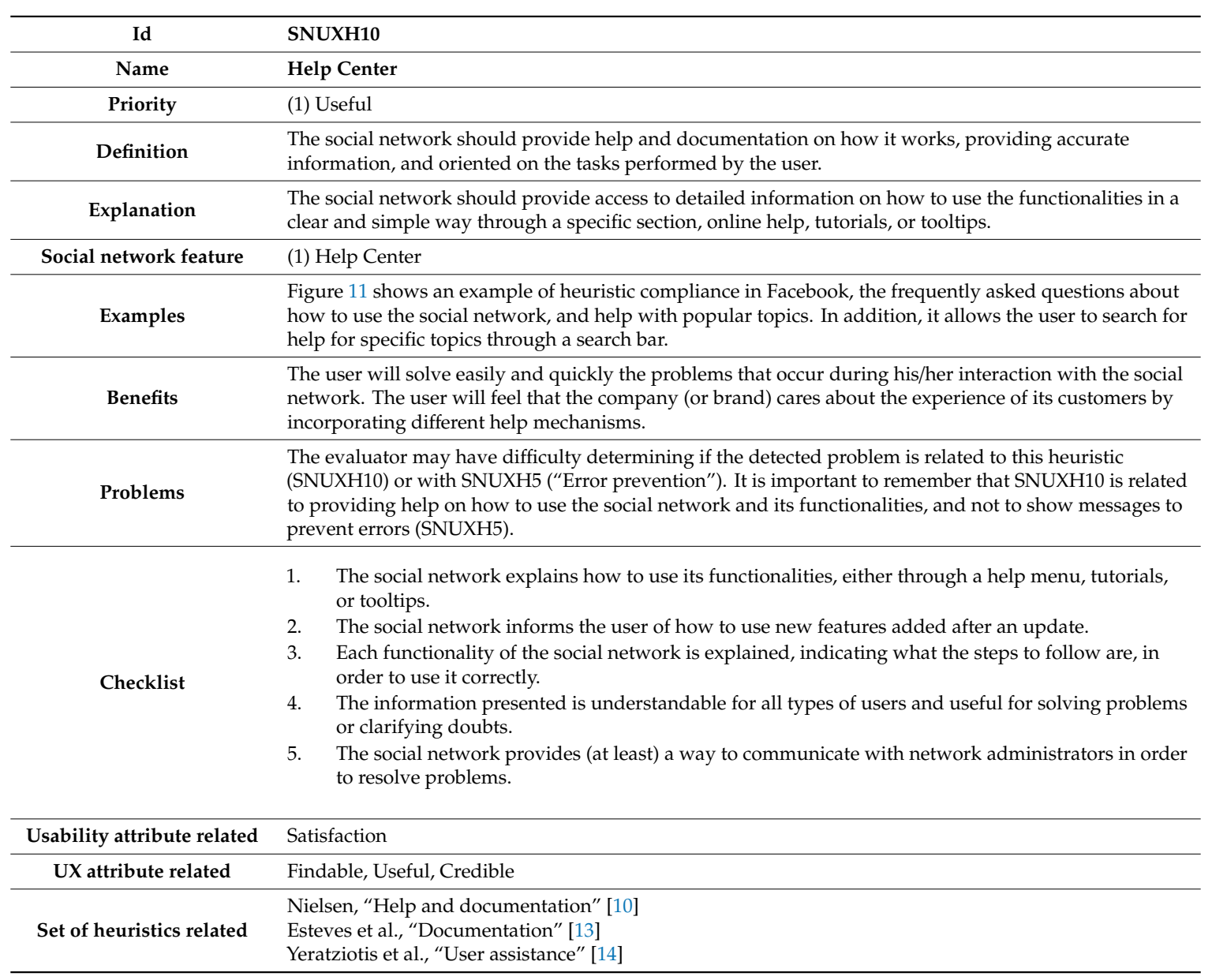




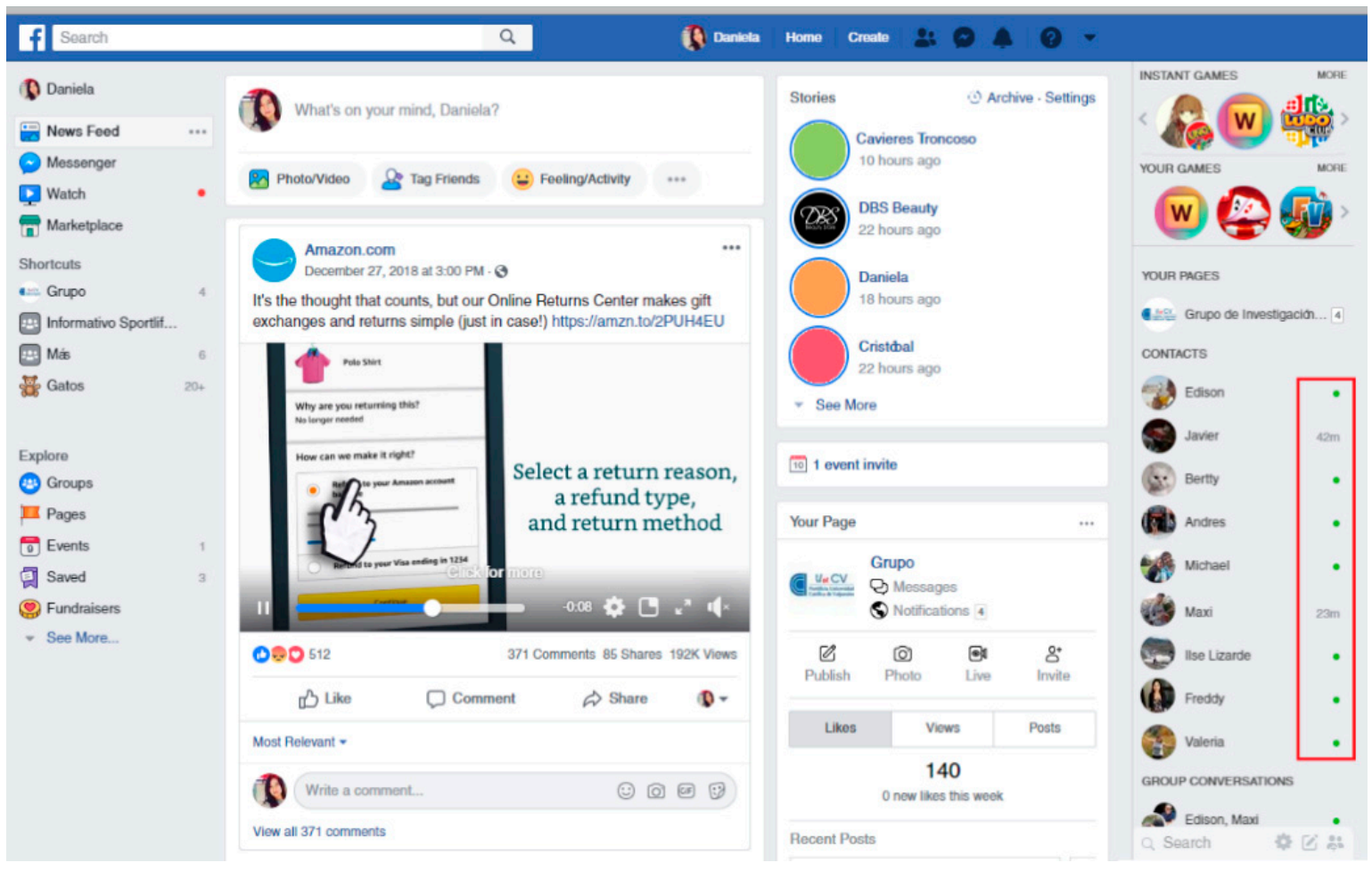

Figure 12. SNUXH11: Perception and user status.

Table 16. SNUXH11: Perception and user status.

\begin{tabular}{|c|c|}
\hline Id & SNUXH11 \\
\hline Name & Perception and User Status \\
\hline Priority & (2) Important \\
\hline Social network feature & (1) Customization, (2) Connectivity, and (3) Interaction \\
\hline Examples & $\begin{array}{l}\text { Figure } 12 \text { shows an example of heuristic compliance in Facebook, the users who are online and available } \\
\text { to chat (green circular icon), and disconnected users (minutes taken offline). }\end{array}$ \\
\hline Problems & $\begin{array}{l}\text { This heuristic should not be confused with SNUXH8 ("Flexibility and customization"). SNUXH11 refers } \\
\text { to how other users of the social network perceive the user (their status). SNUXH8 refers to flexibility } \\
\text { regarding the interface and to customize the visualization of functionalities and content (not } \\
\text { customization of user status). }\end{array}$ \\
\hline
\end{tabular}

1. The social network allows the user to decide how he/she want to be perceived by all or some of their contacts.

2. The social network allows changing user availability (status) at any time.

3. The social network allows visualizing the status of the other contacts of the user for their interaction (through representative icons, colors, or text).

4. The social network allows blocking contacts with which the user does not want to interact.

5. The social network allows the user to silence contacts who he/she does not want to read his/her comments or publications.

\begin{tabular}{cl}
\hline Usability attribute related & Satisfaction \\
\hline UX attribute related & Usable, Desirable \\
\hline Set of heuristics related & Esteves et al., "Perception of Users" and "User's status" [13] \\
\hline
\end{tabular}




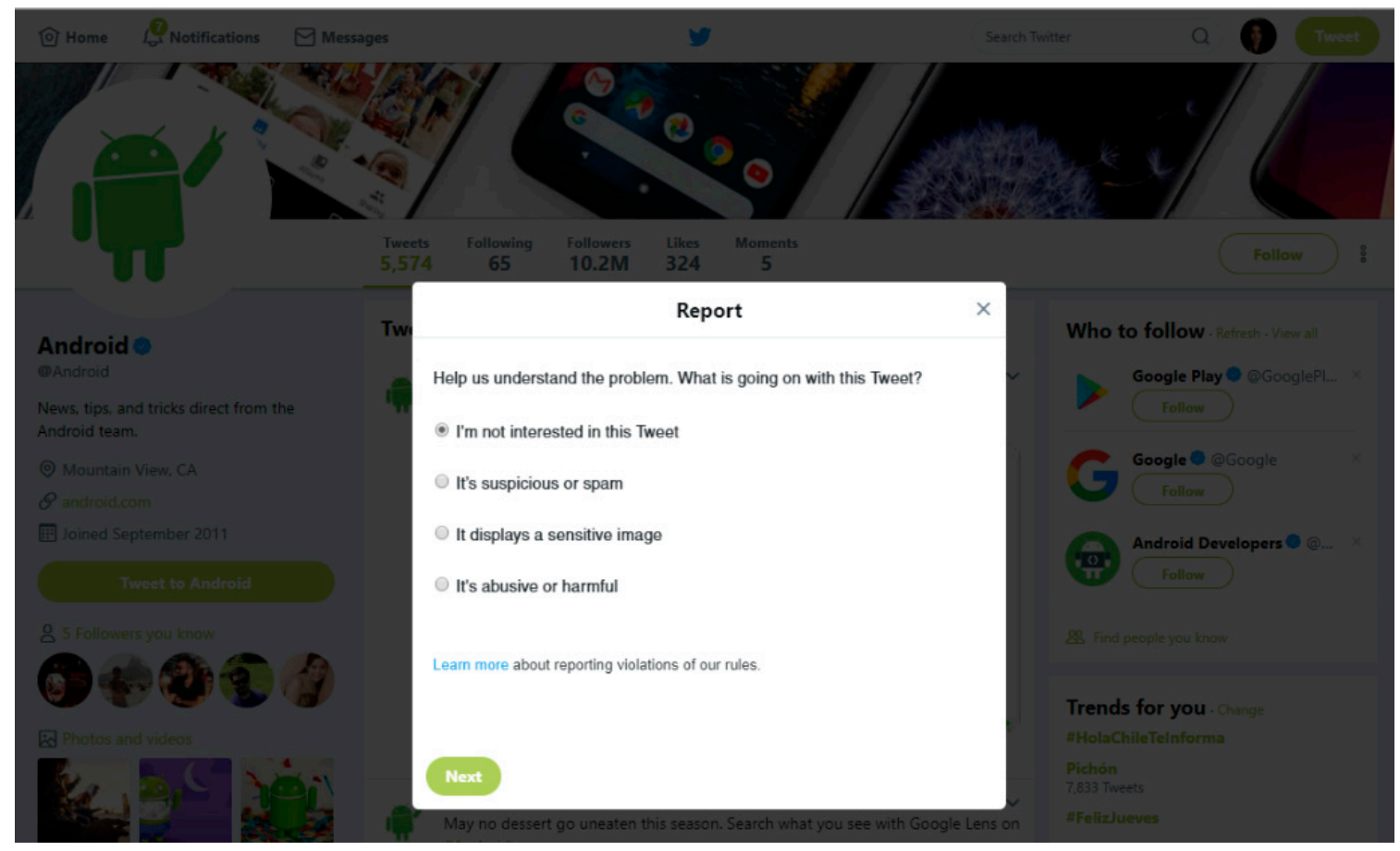

Figure 13. SNUXH12: Control the published content.

Table 17. SNUXH12: Control the published content.

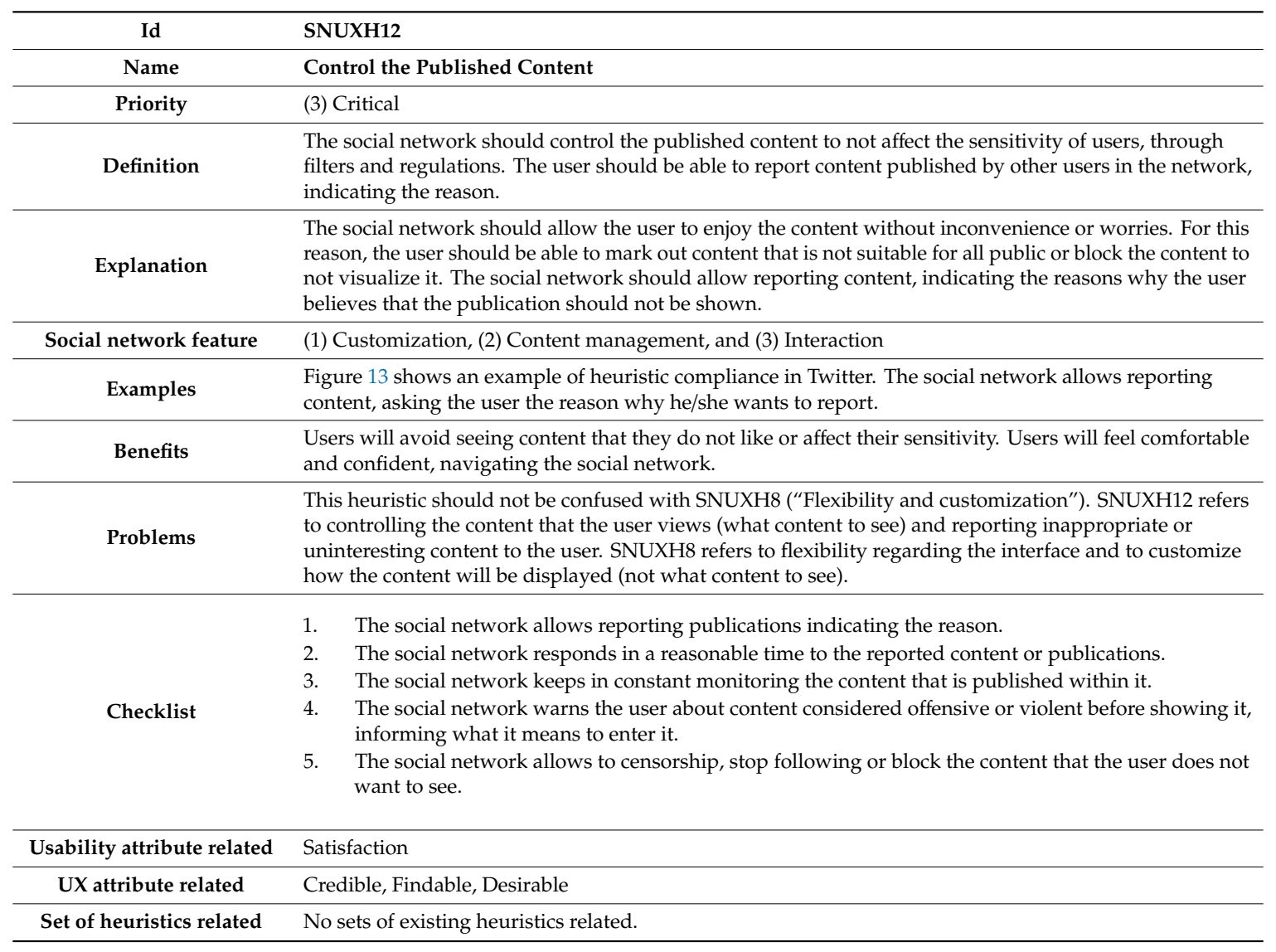




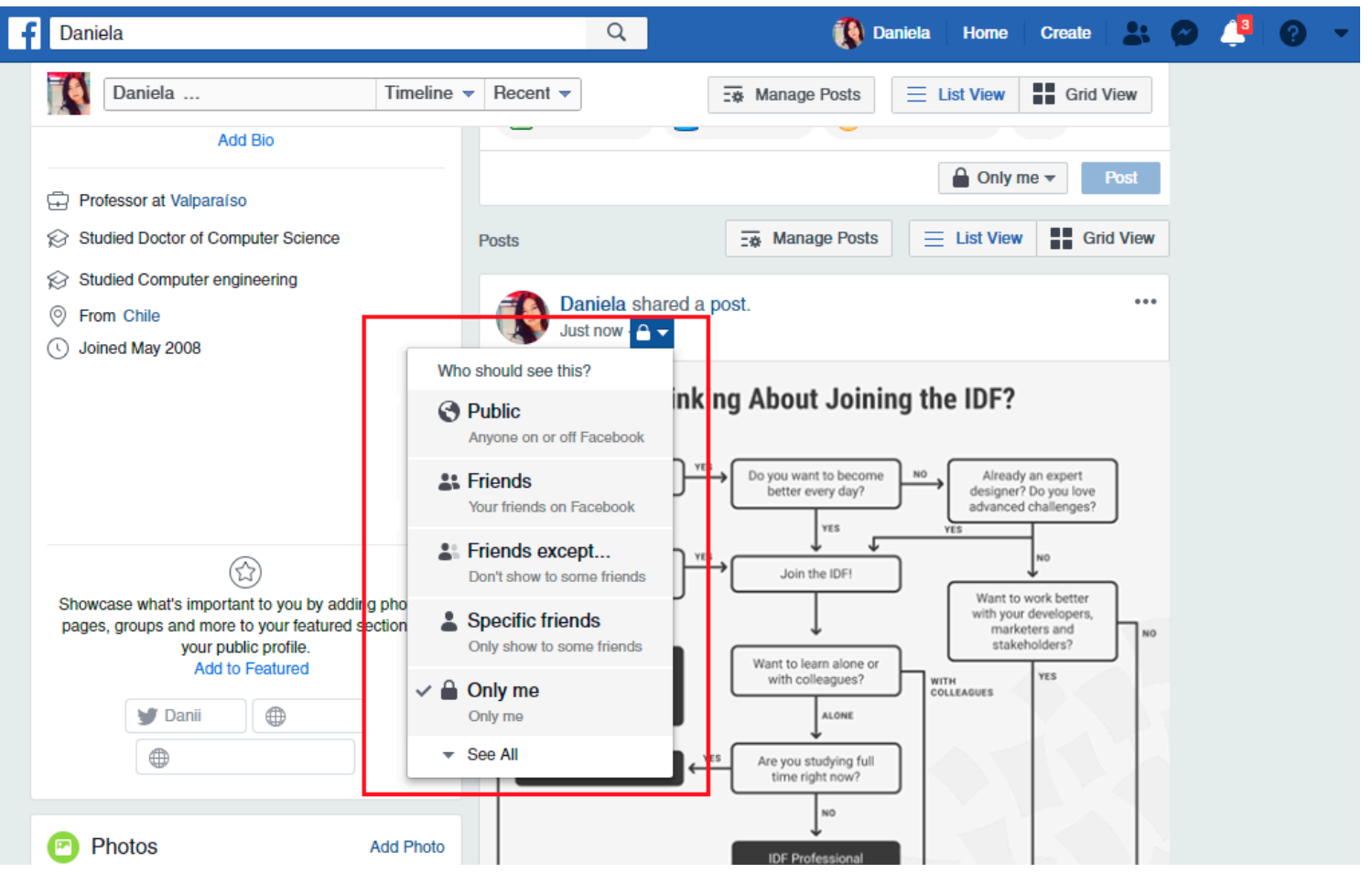

Figure 14. SNUXH13: Privacy control.

Table 18. SNUXH13: Privacy control.

\begin{tabular}{|c|c|}
\hline Id & SNUXH13 \\
\hline Name & Privacy Control \\
\hline Priority & (3) Critical \\
\hline Explanation & $\begin{array}{l}\text { The social network should allow the user to restrict access to their information (personal data, } \\
\text { publications, photos, comments, etc.), giving them the possibility to decide who can view their } \\
\text { information. The social network should predefine minimum privacy for new users and allow changing } \\
\text { the privacy settings at any time. }\end{array}$ \\
\hline Social network feature & (1) Customization, (2) Security, and (3) Interaction \\
\hline Examples & $\begin{array}{l}\text { Figure } 14 \text { shows an example of heuristic compliance in Facebook, how to control who can see a publication } \\
\text { shared by the user ("public", "friends", "friends except ... ", "specific friends", and "only me"). }\end{array}$ \\
\hline Benefits & $\begin{array}{l}\text { The user will feel safe using the social network, knowing that he/she can control who visualizes his/her } \\
\text { information and who can access their personal content. }\end{array}$ \\
\hline Checklist & $\begin{array}{l}\text { 1. The social network allows selecting the audience that can view the user profile and its content. } \\
\text { 2. The social network has a reasonable privacy configuration of information for new users. } \\
\text { 3. The social network maintains minimum privacy between users who interact with each other } \\
\text { through instant messaging, ensuring that their information will not be disclosed on the network. } \\
\text { 4. The social network allows users to choose who can (or cannot) access to their profile and its content. }\end{array}$ \\
\hline Usability attribute related & Satisfaction \\
\hline UX attribute related & Credible, Desirable \\
\hline
\end{tabular}




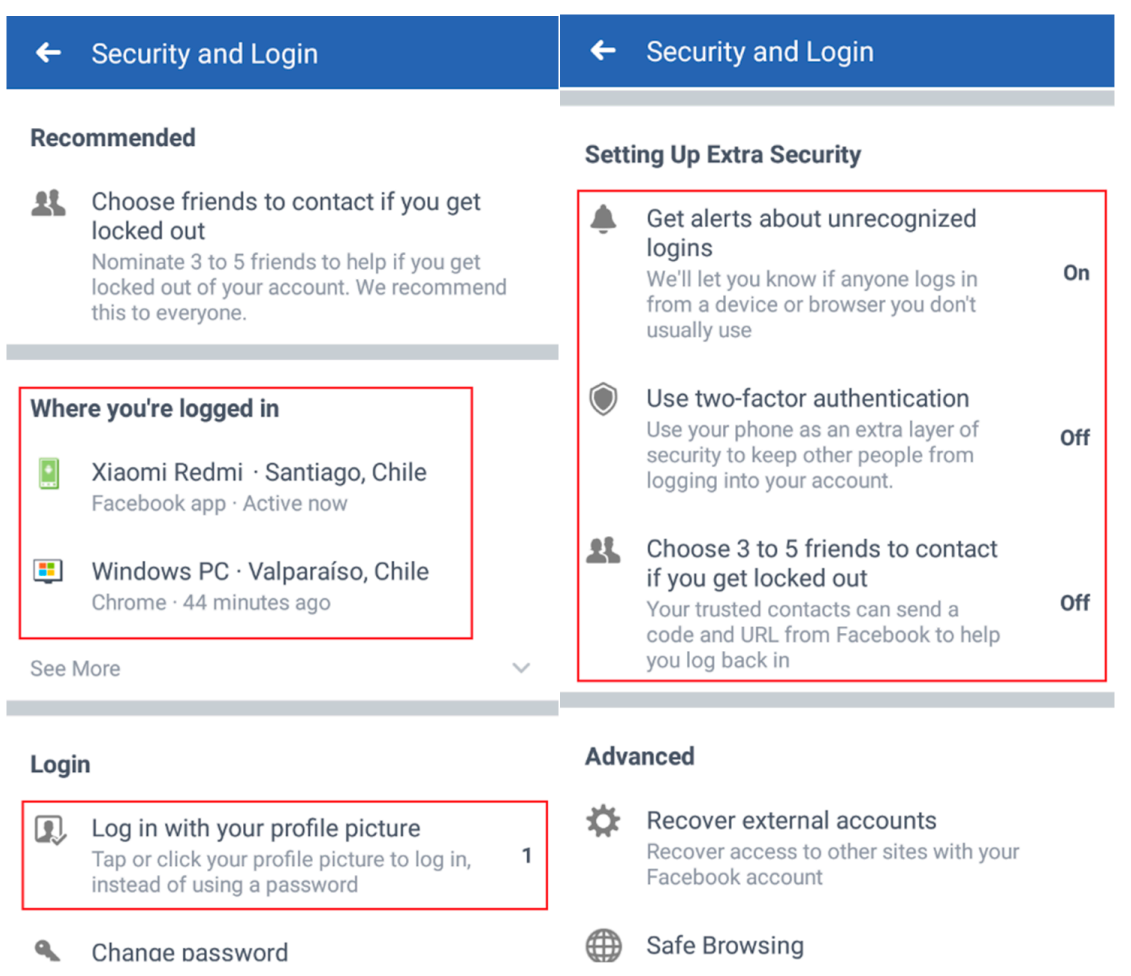

Figure 15. SNUXH14: Security and recovery of user account.

Table 19. SNUXH14: Security and recovery of user account.

\begin{tabular}{|c|c|}
\hline Id & SNUXH14 \\
\hline Priority & (3) Critical \\
\hline Definition & $\begin{array}{l}\text { The social network must include security measures, account recovery account protection, and personal } \\
\text { data of the user. }\end{array}$ \\
\hline Explanation & $\begin{array}{l}\text { The social network must include security options that assure the user a total protection of their personal } \\
\text { information. In addition, the social network must notify the user about situations that could affect the } \\
\text { security of its content and personal information and provide mechanisms to recover the account. }\end{array}$ \\
\hline Social network feature & (1) Security, and (2) Customization \\
\hline Examples & $\begin{array}{l}\text { Figure } 15 \text { shows an example of heuristic compliance in Facebook. The social network displays where the } \\
\text { user is logged in, different methods to login, and options such as: "get alerts about unrecognized logins", } \\
\text { "use two-factor authentication", and "choose friends to contact if you get locked out". }\end{array}$ \\
\hline Benefits & $\begin{array}{l}\text { The user will feel safe to include their personal information in the social network and to share contents. } \\
\text { The above generates loyal customers with the brand or company. }\end{array}$ \\
\hline Checklist & $\begin{array}{l}\text { 1. The social network has at least one mechanism for account recovery (e.g., by email or text message } \\
\text { to smartphone). } \\
\text { The social network includes a section to review the user logon history on different devices } \\
\text { or platforms. } \\
\text { 3. The social network allows modifying the user's password. } \\
\text { 4. The social network suggests security measures for the password of the account associated with the } \\
\text { user, as a minimum number of characters. } \\
\text { The social network includes an option that allows the user to receive a notification when a new login } \\
\text { is made from his account on other platforms. }\end{array}$ \\
\hline
\end{tabular}




\section{Conclusions}

Social networks are used for different purposes, but users always expect the interaction to be natural, pleasant, and intuitive, without the need for instructions or explanations, and above all, without problems. Evaluating the UX is essential to detect which elements hinder the interaction or bother the user, to then correct those problems and improve the user experience. Since social networks are applications with specific features, it is necessary to use a specific instrument. Even though there are sets of heuristics to evaluate usability in social networks [13-15], those sets evaluate only some attributes of the UX (such as usability).

We proposed a set of 14 heuristics to evaluate the UX for social networks: SNUXH. The heuristics were developed using a standard template and are oriented to evaluate both UX aspects (useful, usable, desirable, findable, and credible) and usability attributes (effectiveness, efficiency, and satisfaction). Evaluators decide what elements of the heuristic's specification use in a heuristic evaluation, depending on their knowledge, experience, time, and needs. We recommend using at least the id, name, description, and examples in the evaluation process, for obtaining better results.

SNUXH were developed following a formal process using the methodology proposed by Quiñones et al. [6,7], and with a greater level of detail compared to other existing sets [13-15]. Applying the methodology allowed us to obtain a set of well-defined heuristics. We experimentally validated SNUXH in four iterations, through expert judgment, heuristic evaluation, and co-discovery tests.

Based on the results obtained in the validations performed, we conclude that SNUXH are effective, since they obtained better results than the control heuristics (Nielsen's heuristics [10]) in the heuristic evaluation carried out in the first iteration, for all criteria evaluated [6,7]. In addition, in the second iteration, the experts perceived SNUXH as useful and easy to use. The feedback received by the experts in the third iteration allowed us to refine and improve SNUXH.

Since usability heuristics are principles for interaction design [10,32], we believe that heuristics can be used as a guide for social network design. To create social networks, SNUXH can be used as a support to avoid designing interfaces that generate usability and/or user experience problems. On the other hand, to improve the design of existing social networks, SNUXH can be used to detect usability/UX potential problems and then correct these problems, and thus, improve the user experience.

The current work has some limitations. In the first iteration, we validated SNUXH through heuristic evaluations using a case study the social network Facebook. Even though we obtained useful information to refine and improve the heuristics; it is necessary to evaluate the effectiveness of heuristics evaluating other social networks, such as Twitter, Instagram, among others. In the third iteration, we validated SNUXH through a user test (a Co-discovery test). In this test, participated users of 21-26 years old. This age range represents a type of user profile (young people), so it is necessary to work with users of other ages to determine what other problems they have used social networks.

In future work, we plan to validate and refine SNUXH by evaluating other social networks (in addition to Facebook), and selecting case studies for both desktop and mobile.

Author Contributions: Conceptualization, D.Q. and C.R.; methodology, D.Q.; validation, D.A., S.G. and M.J.S.; formal analysis, D.A., S.G. and M.J.S.; investigation, D.A., S.G. and M.J.S.; resources, D.Q. and C.R.; data curation, D.A., S.G. and M.J.S.; writing—original draft preparation, D.Q.; writing-review and editing, D.Q.; project administration, D.Q. and C.R.; funding acquisition, D.Q. All authors have read and agreed to the published version of the manuscript.

Funding: Daniela Quiñones is supported by Grant ANID (ex CONICYT), Chile, FONDECYT INICIACIÓN, Project No 11190759 .

Acknowledgments: The authors would like to thank all the participants (experts and researchers) who were involved in the experiments for this study, especially the members of the "UseCV" Research Group in Human-Computer Interaction (School of Informatics Engineering, Pontificia Universidad Católica de Valparaíso-Chile). Daniela Quiñones is supported by Grant ANID (ex CONICYT), Chile, FONDECYT INICIACIÓN, Project N 11190759.

Conflicts of Interest: The authors declare no conflict of interest. 


\section{Appendix A}

Table A1. Inputs, outputs, and activities for each step performed in iteration 1.

\begin{tabular}{cl}
\hline Step & \multicolumn{1}{c}{ Input } \\
\hline Step 1: Exploratory stage & $\begin{array}{l}\text { Social network domain (both } \\
\text { desktop and mobile } \\
\text { applications) }\end{array}$
\end{tabular}

\section{(1) Information about social} networks (three definitions, one classification, and six features); (2) two proposals for usability attributes and three proposals for UX attributes; and (3) four existing sets of heuristics related.
Activities Performed

Conduct a literature review about: social networks (definitions, classifications, and features); usability/UX attributes; and existing sets of usability/UX heuristics related

Step 2: Experimental stage $\begin{aligned} & \text { Social network domain (both } \\ & \text { desktop and mobile } \\ & \text { applications) }\end{aligned}$

\section{(5) Fifty-two detected} usability/UX problems and (6) Problems with existing heuristics
- Perform a heuristic evaluation to Facebook, using three sets of heuristics [10,13,14].

\begin{tabular}{|c|c|c|c|c|}
\hline Step 3: Descriptive stage & $\begin{array}{l}\text { (1) Information about social } \\
\text { networks (three definitions, } \\
\text { one classification, and six } \\
\text { features); (2) two proposals } \\
\text { for usability attributes and } \\
\text { three proposals for UX } \\
\text { attributes; and (3) four } \\
\text { existing sets of heuristics } \\
\text { related; and (5) } 52 \text { detected } \\
\text { usability problems }\end{array}$ & $\begin{array}{l}(7) \text { Selected information } \\
\text { about social networks; (8) six } \\
\text { selected features of social } \\
\text { networks; (9) three selected } \\
\text { usability attributes (from one } \\
\text { proposal) and five UX } \\
\text { attributes (from one } \\
\text { proposal); and (10 three } \\
\text { selected sets of heuristics. }\end{array}$ & - & $\begin{array}{l}\text { Group the } \\
\text { information collected. } \\
\text { Sort and prioritize the } \\
\text { information using a } \\
\text { three-level scale ( } 3 \text { : highly } \\
\text { important; 2: somewhat } \\
\text { important; } 1 \text { : not } \\
\text { important). } \\
\text { Select the information to } \\
\text { develop the heuristics. }\end{array}$ \\
\hline Step 4: Correlational stage & $\begin{array}{l}\text { (7) Selected information } \\
\text { about social networks; (8) six } \\
\text { selected features of social } \\
\text { networks; (9) three selected } \\
\text { usability attributes (from one } \\
\text { proposal) and five UX } \\
\text { attributes (from one } \\
\text { proposal); and (10 three } \\
\text { selected sets of heuristics }\end{array}$ & $\begin{array}{l}11 \text { Matched features, } \\
\text { attributes, and existing } \\
\text { heuristics }\end{array}$ & - & $\begin{array}{l}\text { Match the six social } \\
\text { network features with the } \\
\text { three usability attributes, } \\
\text { five UX attributes, and } \\
\text { three sets of heuristics (10 } \\
\text { Nielsen heuristics [10], } 8 \\
\text { Esteves et al. heuristics } \\
\text { [13], and } 16 \text { Yeratziotis et } \\
\text { al. heuristics [14]. Total: } \\
34 \text { heuristics) } \\
\text { The new heuristics will not } \\
\text { be grouped into categories }\end{array}$ \\
\hline Step 5: Selection stage & $\begin{array}{l}\text { (10) three selected sets of } \\
\text { heuristics; } 11 \text { Matched } \\
\text { features, attributes, and } \\
\text { existing heuristics }\end{array}$ & $\begin{array}{l}13 \text { Classified heuristics (zero } \\
\text { to keep; } 25 \text { to adapt; one to } \\
\text { create; and nine to eliminate) }\end{array}$ & & $\begin{array}{l}\text { Review Nielsen, } \\
\text { Yeratziotiz et al., and } \\
\text { Esteves et al. heuristics; } \\
\text { and determine what } \\
\text { heuristics to: keep, adapt, } \\
\text { create, and eliminate. } \\
\text { Identify which existing } \\
\text { heuristics can be join } \\
\text { into one }\end{array}$ \\
\hline Step 6: Specification stage & $\begin{array}{l}\text { (6) Problems with existing } \\
\text { heuristics; } 11 \text { Matched } \\
\text { features, attributes, and } \\
\text { existing heuristics; } \mathbb{1 3} \\
\text { Classified heuristics (zero to } \\
\text { keep; } 25 \text { to adapt; one to } \\
\text { create; and nine to eliminate) }\end{array}$ & $\begin{array}{l}\text { 14 Set of social network } \\
\text { heuristics, SNH (first } \\
\text { iteration) }\end{array}$ & & $\begin{array}{l}\text { Specify } 16 \text { UX heuristics } \\
\text { for social networks (SNH), } \\
\text { including: id, priority, } \\
\text { name, definition, } \\
\text { explanation, social } \\
\text { network feature, examples, } \\
\text { benefits, problems, } \\
\text { usability/UX attribute, and } \\
\text { existing heuristics related } \\
\text { (checklist not included) }\end{array}$ \\
\hline
\end{tabular}


Table A1. Cont.

\begin{tabular}{|c|c|c|c|}
\hline Step & Input & Output & Activities Performed \\
\hline Step 7: Validation stage & $\begin{array}{l}\text { 14 Set of social network } \\
\text { heuristics, SNH (first } \\
\text { iteration) }\end{array}$ & $\begin{array}{l}15 \text { Heuristic evaluation } \\
\text { results: effectiveness of } \mathrm{SNH}\end{array}$ & $\begin{array}{l}\text { Perform a heuristic } \\
\text { evaluation to Facebook } \\
\text { with six evaluators (three } \\
\text { evaluators for the control } \\
\text { group, three evaluators for } \\
\text { experimental group) } \\
\text { Evaluate the SNH } \\
\text { effectiveness using } \\
\text { five criteria }\end{array}$ \\
\hline Step 8: Refinement stage & $\begin{array}{l}\text { (5) Heuristic evaluation } \\
\text { results: effectiveness of SNH }\end{array}$ & $\begin{array}{l}18 \text { Refining document: (1) } 16 \\
\text { heuristics to refine, two } \\
\text { heuristics to delete; (2) } \\
\text { repeat steps } 6,7 \text {, and } 8\end{array}$ & $\begin{array}{l}\text { Document the } \\
\text { improvements to be } \\
\text { performed in the } \\
\text { specification of } \mathrm{SNH} \\
\text { It is decided to iterate } \\
\text { repeating stages } 6,7 \text {, and } 8\end{array}$ \\
\hline
\end{tabular}

\section{Appendix B}

Table A2. Inputs, outputs, and activities for each step performed in iteration 2.

\begin{tabular}{|c|c|c|c|}
\hline Step & Input & Output & Activities Performed \\
\hline Step 7: Validation stage & $\begin{array}{l}\text { 14 Set of social network heuristics, } \\
\text { SNWH (second iteration) }\end{array}$ & (16) Expert judgment results (survey) & $\begin{array}{l}\text { Apply a survey to three } \\
\text { experts in order to capture the } \\
\text { evaluators' perception about } \\
\text { SNWH set in four dimensions } \\
\text { (utility, } \\
\text { clarity, ease of use, and need for } \\
\text { additional elements-checklists) }\end{array}$ \\
\hline Step 8: Refinement stage & (16) Expert judgment results (survey) & $\begin{array}{l}18 \text { Refining document: (1) eight } \\
\text { heuristics to refine, two heuristics to } \\
\text { delete, two heuristics to create, two } \\
\text { heuristics to join into one; (2) repeat } \\
\text { steps } 6,7 \text {, and } 8\end{array}$ & $\begin{array}{l}\text { Document the improvements } \\
\text { to be performed in the } \\
\text { specification of SNWH } \\
\text { It is decided to iterate } \\
\text { repeating stages } 6,7 \text {, and } 8\end{array}$ \\
\hline
\end{tabular}




\section{Appendix C}

Table A3. Inputs, outputs, and activities for each step performed in iteration 3.

\begin{tabular}{|c|c|c|c|}
\hline Step & Input & Output & Activities Performed \\
\hline Step 6: Specification stage & $\begin{array}{l}\text { 14 Set of social network heuristics, } \\
\text { SNWH (second iteration); } 18 \\
\text { Refining document: (1) eight } \\
\text { heuristics to refine, two heuristics } \\
\text { to delete, two heuristics to create, } \\
\text { two heuristics to join into one; (2) } \\
\text { repeat steps } 6,7 \text {, and } 8\end{array}$ & $\begin{array}{l}\text { 14 Set of social network } \\
\text { heuristics, SNXH (third } \\
\text { iteration) }\end{array}$ & $\begin{array}{l}\text { Refine and improve the } \\
\text { specification of } 12 \text { UX } \\
\text { heuristics for social networks } \\
\text { (SNXH) }\end{array}$ \\
\hline Step 7: Validation stage & $\begin{array}{l}\text { 14 Set of social network heuristics, } \\
\text { SNXH (third iteration) }\end{array}$ & $\begin{array}{l}\text { 16 Expert opinion results; } 18 \\
\text { User tests results: users' } \\
\text { perceptions }\end{array}$ & $\begin{array}{l}\text { Perform a co-discovery test to } \\
\text { evaluate Facebook with eight } \\
\text { users (four groups, two users } \\
\text { per group). Based on the } \\
\text { results: (1) validate if the } \\
\text { usability/UX problems } \\
\text { identified in the heuristic } \\
\text { evaluation (first iteration) are } \\
\text { perceived as real problems for } \\
\text { the users; and (2) identify new } \\
\text { problems and review if these } \\
\text { problems are evaluated by the } \\
\text { SNXH set } \\
\text { Conduct an interview with } \\
\text { two experts to evaluate SNXH } \\
\text { set in terms of: overall utility, } \\
\text { completeness, and readability }\end{array}$ \\
\hline Step 8: Refinement stage & $\begin{array}{l}\text { (16) Expert opinion results; } \mathbb{1 D} \text { User } \\
\text { tests results: users' perceptions }\end{array}$ & $\begin{array}{l}18 \text { Refining document: (1) four } \\
\text { heuristics to refine, one } \\
\text { heuristic to delete, four } \\
\text { heuristics to create, one } \\
\text { heuristic to separate into two; } \\
\text { (2) repeat step } 6\end{array}$ & $\begin{array}{l}\text { Document the improvements } \\
\text { to be performed in the } \\
\text { specification of SNXH } \\
\text { It is decided to iterate } \\
\text { repeating stage } 6\end{array}$ \\
\hline
\end{tabular}

\section{Appendix D}

Table A4. Inputs, outputs, and activities for each step performed in iteration 4.

\begin{tabular}{|c|c|c|c|}
\hline Step & Input & Output & Activities Performed \\
\hline
\end{tabular}




\section{Appendix E}

Table A5. Set of heuristics for social networks developed at each iteration.

\begin{tabular}{|c|c|c|c|}
\hline First Iteration (SNH) & $\begin{array}{l}\text { Second Iteration } \\
\text { (SNWH) }\end{array}$ & Third Iteration (SNXH) & $\begin{array}{l}\text { Fourth Iteration } \\
\quad \text { (SNUXH) }\end{array}$ \\
\hline $\begin{array}{l}\text { SNH1: Visibility of } \\
\text { system status }\end{array}$ & $\begin{array}{l}\text { SNWH1: Visibility of } \\
\text { elements and system } \\
\text { status }\end{array}$ & $\begin{array}{l}\text { SNXH1: Visual feedback } \\
\text { and system status }\end{array}$ & $\begin{array}{l}\text { SNUXH1: Visual } \\
\text { feedback and social } \\
\text { network status }\end{array}$ \\
\hline $\begin{array}{l}\text { SNH2: Visibility of } \\
\text { system elements and } \\
\text { important information }\end{array}$ & $\begin{array}{l}\text { SNWH2: Perception and } \\
\text { user status }\end{array}$ & $\begin{array}{l}\text { SNXH2: Design and } \\
\text { interface }\end{array}$ & $\begin{array}{l}\text { SNUXH2: Match } \\
\text { between the social } \\
\text { network and real world }\end{array}$ \\
\hline $\begin{array}{l}\text { SNH3: Perception and } \\
\text { user status }\end{array}$ & $\begin{array}{l}\text { SNWH3: Match between } \\
\text { system and the real } \\
\text { world }\end{array}$ & $\begin{array}{l}\text { SNXH3: Perception and } \\
\text { user status }\end{array}$ & $\begin{array}{l}\text { SNUXH3: User control } \\
\text { and freedom }\end{array}$ \\
\hline $\begin{array}{l}\text { SNH4: Match between } \\
\text { system and the real } \\
\text { world }\end{array}$ & $\begin{array}{l}\text { SNWH4: Consistency } \\
\text { and standards between } \\
\text { system elements }\end{array}$ & $\begin{array}{l}\text { SNXH4: Minimize the } \\
\text { user's memory load }\end{array}$ & $\begin{array}{l}\text { SNUXH4: Consistency } \\
\text { and standards in } \\
\text { multiplatform }\end{array}$ \\
\hline $\begin{array}{l}\text { SNH5: Consistency and } \\
\text { standards between } \\
\text { system elements }\end{array}$ & $\begin{array}{l}\text { SNWH5: User control } \\
\text { and freedom }\end{array}$ & $\begin{array}{l}\text { SNXH5: Prevention and } \\
\text { recovery from errors }\end{array}$ & $\begin{array}{l}\text { SNUXH5: Error } \\
\text { prevention }\end{array}$ \\
\hline $\begin{array}{l}\text { SNH6: Consistency in } \\
\text { design and web } \\
\text { symbology }\end{array}$ & $\begin{array}{l}\text { SNWH6: Error } \\
\text { prevention }\end{array}$ & $\begin{array}{l}\text { SNXH6: User control } \\
\text { and freedom }\end{array}$ & $\begin{array}{l}\text { SNUXH6: Minimize the } \\
\text { user's memory load }\end{array}$ \\
\hline $\begin{array}{l}\text { SNH7: User control and } \\
\text { freedom }\end{array}$ & $\begin{array}{l}\text { SNWH7: Minimize the } \\
\text { user's memory load }\end{array}$ & $\begin{array}{l}\text { SNXH7: Content control } \\
\text { published }\end{array}$ & $\begin{array}{l}\text { SNUXH7: Aesthetic and } \\
\text { minimalist design }\end{array}$ \\
\hline SNH8: Error prevention & $\begin{array}{l}\text { SNWH8: Flexibility and } \\
\text { efficiency of use }\end{array}$ & $\begin{array}{l}\text { SNXH8: Alert and } \\
\text { notification control }\end{array}$ & $\begin{array}{l}\text { SNUXH8: Flexibility and } \\
\text { customization }\end{array}$ \\
\hline $\begin{array}{l}\text { SNH9: Minimize the } \\
\text { user's memory load }\end{array}$ & $\begin{array}{l}\text { SNWH9: Aesthetic and } \\
\text { minimalist design }\end{array}$ & $\begin{array}{l}\text { SNXH9: Privacy and } \\
\text { exposure control }\end{array}$ & $\begin{array}{l}\text { SNUXH9: Help users } \\
\text { recognize, diagnose, and } \\
\text { recover from errors }\end{array}$ \\
\hline $\begin{array}{l}\text { SNH10: Flexibility and } \\
\text { efficiency of use }\end{array}$ & $\begin{array}{l}\text { SNWH10: Help user to } \\
\text { recognize, diagnose, and } \\
\text { recover from errors }\end{array}$ & $\begin{array}{l}\text { SNXH10: Security and } \\
\text { recovery of user account }\end{array}$ & SNUXH10: Help Center \\
\hline $\begin{array}{l}\text { SNH11: Aesthetic and } \\
\text { minimalist design }\end{array}$ & $\begin{array}{l}\text { SNWH11: Help and } \\
\text { documentation }\end{array}$ & SNXH11: Help center & $\begin{array}{l}\text { SNUXH11: Perception } \\
\text { and user status }\end{array}$ \\
\hline $\begin{array}{l}\text { SNH12: Help user to } \\
\text { recognize, diagnose, and } \\
\text { recover from errors }\end{array}$ & $\begin{array}{l}\text { SNWH12: Privacy and } \\
\text { exposure control }\end{array}$ & $\begin{array}{l}\text { SNXH12: Consistency } \\
\text { between platforms }\end{array}$ & $\begin{array}{l}\text { SNUXH12: Control the } \\
\text { published content }\end{array}$ \\
\hline $\begin{array}{l}\text { SNH13: Help and } \\
\text { documentation }\end{array}$ & $\begin{array}{l}\text { SNWH13: Content } \\
\text { control published }\end{array}$ & & $\begin{array}{l}\text { SNUXH13: Privacy } \\
\text { control }\end{array}$ \\
\hline $\begin{array}{l}\text { SNH14: Privacy and } \\
\text { exposure control }\end{array}$ & $\begin{array}{l}\text { SNWH14: Security and } \\
\text { recovery of user account }\end{array}$ & & $\begin{array}{l}\text { SNUXH14: Security and } \\
\text { recovery of user account }\end{array}$ \\
\hline \multicolumn{4}{|l|}{$\begin{array}{l}\text { SNH15: Content control } \\
\text { published }\end{array}$} \\
\hline $\begin{array}{l}\text { SNH16: Security and } \\
\text { recovery of user account }\end{array}$ & & & \\
\hline
\end{tabular}




\section{Appendix F}

Table A6. Step 2: "Experimental stage". Results were obtained in the heuristic evaluation.

\begin{tabular}{ll}
\hline \multicolumn{1}{c}{ Experiment Performed } & Heuristic Evaluation \\
\hline Application evaluated & Facebook \\
\hline $\begin{array}{l}\text { Set of usability heuristics } \\
\text { used }\end{array}$ & $\begin{array}{l}\text { Three sets of heuristics were used to perform the heuristic evaluation: (1) } \\
\text { Nielsen's heuristics [10], (2) Esteves et al. heuristics [13], and (3) Yeratziotis et } \\
\text { al. heuristics [14]. }\end{array}$ \\
\hline Amount of evaluators & $\begin{array}{l}\text { Three evaluators with similar experience performing heuristic evaluations } \\
\text { and using sets of heuristics }\end{array}$ \\
\hline
\end{tabular}

- How each set of heuristics cover the usability/UX problems detected

- Correct and incorrect associations of problems to heuristics

- $\quad$ Problems with existing heuristics (such as unclear definitions, lack of

Elements analyzed detail in the heuristic specification, superposition of heuristics, among others)

- Identify if it is necessary to create new heuristics to evaluate social network specific features and/or usability/UX attributes

Results: Detected usability problems and problems with existing heuristics
- 52 usability/UX problems detected

- Nielsen's heuristics [10] covers $75 \%$ of the problems detected; Esteves et al. heuristics [13] covers $60 \%$ of the problems detected; and Yeratziotis et al. heuristics [14] covers $56 \%$ of the problems detected. This analysis was performed by the evaluators taking into account: (1) the social network features, the usability/UX attributes associated with each detected problem, and (2) the extent to which each set of heuristics allows to evaluate the application effectively (detect problems)

- $\quad$ Regarding Nielsen's heuristics [10]: three heuristics with few associated problems (equal or less than two problems). These heuristics have an unclear definition: NH3: "User control and freedom", NH6:

"Recognition rather than recall", and NH7: "Flexibility and efficiency of use".

- $\quad$ Regarding Esteves et al. heuristics [13]: Two heuristics with the highest number of incorrect associations, due to unclear definitions (four incorrect associations for EH5: "Control for relationship" and seven incorrect associations for EH7: "Consistency"). Evaluators detected usability problems that were not covered by the set of heuristics (it is necessary to create a heuristic to evaluate the aesthetic and minimalist design).

- $\quad$ Regarding Yeratziotis et al. heuristics [14]: Three heuristics with few associated problems (less than two problems), and also with incorrect associations. These heuristics are difficult to understand: YH7: "Errors", YH9: "User suitability", and YH10: "User language". In general, this set of heuristics was difficult to use because it is very specific (focused on security in online health social networks). 


\section{Appendix G}

Table A7. Step 3: "Descriptive stage". Relevance for social network features, usability/UX attributes, and sets of existing heuristics.

\begin{tabular}{|c|c|c|c|c|}
\hline \multicolumn{5}{|c|}{$\begin{array}{l}\text { Value according to Relevance (3: Highly Important, 2: Somewhat } \\
\text { Important, 1: Not Important) }\end{array}$} \\
\hline Topic & 3 & 2 & 1 & Explanation \\
\hline Social network feature & $\begin{array}{l}\text { Security, Connectivity, } \\
\text { Interaction, Customization, } \\
\text { Content management }\end{array}$ & Help center & - & $\begin{array}{l}\text { All features were selected, since all of } \\
\text { them were considered relevant (security, } \\
\text { connectivity, interaction, customization, } \\
\text { content management, help center). }\end{array}$ \\
\hline Usability attribute [21] & Effectiveness, Efficiency & Satisfaction & - & $\begin{array}{l}\text { Two proposals for usability attributes } \\
\text { were collected in step 1: Nielsen [26], } \\
\text { valued with grade } 2 \text { of importance; and } \\
\text { ISO standard [21], valued with grade } 3 \text { of } \\
\text { importance. While both proposals are } \\
\text { interesting, we decided to use the } \\
\text { attributes proposed by the ISO standard. } \\
\text { All attributes were selected (effectiveness, } \\
\text { efficiency, satisfaction). }\end{array}$ \\
\hline UX attribute [22] & $\begin{array}{l}\text { Useful, Usable, Desirable, } \\
\text { Findable, Credible }\end{array}$ & - & $\begin{array}{l}\text { Accessible, } \\
\text { Valuable }\end{array}$ & $\begin{array}{l}\text { Three proposals for UX attributes were } \\
\text { collected in step 1: Morville [22], valued } \\
\text { with grade } 3 \text { of importance; and } \\
\text { Arhippainen and Tähti [23], and } \\
\text { Kankainen [24], both valued with grade } 1 \\
\text { of importance. We decided to use the } \\
\text { attributes proposed by Morville, since } \\
\text { they are more precise. Of these, five } \\
\text { attributes were selected (useful, usable, } \\
\text { desirable, findable, credible). } \\
\text { "Accessibility" attribute was not } \\
\text { considered as it is a broad and complex } \\
\text { topic, which would increase the number } \\
\text { of heuristics considerably. In addition, } \\
\text { there are more detailed accessibility } \\
\text { assessment guidelines [40] that could be } \\
\text { used together with these heuristics to } \\
\text { assess the level of accessibility of a social } \\
\text { network. "Valuable" attribute was not } \\
\text { considered, since it is related to the } \\
\text { sponsors, an element that we considered } \\
\text { does not apply to be evaluated with } \\
\text { heuristics. }\end{array}$ \\
\hline Set of heuristics & $\begin{array}{l}\text { Nielsen's heuristics [10], } \\
\text { Esteves et al. heuristics [13] }\end{array}$ & $\begin{array}{l}\text { Yeratziotis et al. } \\
\text { heuristics [14] }\end{array}$ & Dubois [15] & $\begin{array}{l}\text { Three sets of heuristics were selected } \\
{[10,13,14] \text {. Dubois }[15] \text { proposes aspects }} \\
\text { and categories for social networks instead } \\
\text { of heuristics, which makes the instrument } \\
\text { difficult to use in a heuristic evaluation. }\end{array}$ \\
\hline
\end{tabular}

\section{Appendix $\mathbf{H}$}

Table A8. Step 4: “Correlational stage". Match between the social network features, usability/UX attributes, and heuristics proposed by other authors.

\begin{tabular}{|c|c|c|}
\hline Feature & Attribute & Heuristic \\
\hline Security & Credible (UX), Efficiency (usability) & $\begin{array}{l}\text { EH1: "Privacy and exhibition control" [13], YH1: } \\
\text { "Visibility", YH13: "Privacy", and YH16: } \\
\text { "Confidentiality" [14] (partially covered) }\end{array}$ \\
\hline Connectivity & Desirable (UX), Efficiency (usability) & YH15: “Availability" [14] (slightly covered) \\
\hline Interaction & $\begin{array}{l}\text { Desirable (UX), Usable (UX), Satisfaction } \\
\text { (usability) }\end{array}$ & $\begin{array}{l}\text { EH5: “Control for relationship” [13] (slightly } \\
\text { covered) }\end{array}$ \\
\hline Customization & $\begin{array}{l}\text { Usable (UX), Desirable (UX), Effectiveness } \\
\text { (usability) }\end{array}$ & $\begin{array}{l}\text { NH7: "Flexibility and efficiency of use" [10] (slightly } \\
\text { covered) }\end{array}$ \\
\hline Content management & $\begin{array}{l}\text { Credible (UX), Findable (UX), Useful (UX), } \\
\text { Effectiveness (usability) }\end{array}$ & EH3: “User status” [13] (slightly covered) \\
\hline Help center & Credible (UX), Findable (UX), Useful (UX) & $\begin{array}{l}\text { NH10: "Help and documentation" [10], EH8: } \\
\text { "Documentation" [13], YH11: "User assistance" [14] }\end{array}$ \\
\hline
\end{tabular}




\section{Appendix I}

Table A9. Step 5: "Selection stage". Heuristics' selection process.

\begin{tabular}{|c|c|c|c|c|c|}
\hline ID & Heuristic Name & Action & $\begin{array}{c}\text { Set of } \\
\text { Heuristics }\end{array}$ & Feature Covered & Applicability \\
\hline NH1 & $\begin{array}{l}\text { Visibility of system } \\
\text { status }\end{array}$ & Adapt & [10] & $\begin{array}{l}\text { General feature } \\
\text { (Feedback) }\end{array}$ & (2) Important \\
\hline $\mathrm{NH} 2$ & $\begin{array}{l}\text { Match between system } \\
\text { and the real world }\end{array}$ & Adapt & [10] & $\begin{array}{c}\text { General feature } \\
\text { (intuitive interface) }\end{array}$ & (2) Important \\
\hline NH3 & $\begin{array}{l}\text { User control and } \\
\text { freedom }\end{array}$ & Adapt & [10] & $\begin{array}{l}\text { General feature } \\
\text { (control) }\end{array}$ & (2) Important \\
\hline NH4 & $\begin{array}{l}\text { Consistency and } \\
\text { standards }\end{array}$ & Adapt & [10] & $\begin{array}{l}\text { General feature } \\
\text { (consistency) }\end{array}$ & (2) Important \\
\hline NH5 & Error prevention & Adapt & [10] & $\begin{array}{c}\text { General feature (error } \\
\text { prevention) }\end{array}$ & (2) Important \\
\hline NH6 & $\begin{array}{l}\text { Recognition rather than } \\
\text { recall }\end{array}$ & Adapt & [10] & $\begin{array}{l}\text { General feature } \\
\text { (memory load) }\end{array}$ & (2) Important \\
\hline NH7 & $\begin{array}{l}\text { Flexibility and efficiency } \\
\text { of use }\end{array}$ & Adapt & [10] & $\begin{array}{l}\text { Specific feature } \\
\text { (Customization) }\end{array}$ & (3) Critical \\
\hline NH8 & $\begin{array}{l}\text { Aesthetic and minimalist } \\
\text { design }\end{array}$ & Adapt & [10] & $\begin{array}{l}\text { General feature } \\
\text { (design) }\end{array}$ & (3) Useful \\
\hline NH9 & $\begin{array}{l}\text { Help users recognize, } \\
\text { diagnose, and recover } \\
\text { from errors }\end{array}$ & Adapt & [10] & $\begin{array}{c}\text { General feature } \\
\text { (recovery from errors) }\end{array}$ & (2) Important \\
\hline NH10 & Help and documentation & Adapt & [10] & $\begin{array}{l}\text { Specific feature (Help } \\
\text { center) }\end{array}$ & (3) Critical \\
\hline YH1 & Visibility & $\begin{array}{l}\text { Adapt (join } \\
\text { with NH1) }\end{array}$ & [14] & $\begin{array}{c}\text { General feature } \\
\text { (Feedback); Specific } \\
\text { feature (Security) }\end{array}$ & (3) Critical \\
\hline YH2 & Revocability & $\begin{array}{l}\text { Adapt (join } \\
\text { with NH3) }\end{array}$ & [14] & $\begin{array}{l}\text { General feature } \\
\text { (control) }\end{array}$ & (2) Important \\
\hline YH3 & Clarity & Discard & [14] & - & - \\
\hline YH4 & $\begin{array}{c}\text { Expressiveness, Convey } \\
\text { features }\end{array}$ & Discard & [14] & - & - \\
\hline YH5 & Learnability & Discard & [14] & - & - \\
\hline YH6 & $\begin{array}{l}\text { Aesthetic and minimalist } \\
\text { design }\end{array}$ & $\begin{array}{l}\text { Adapt (join } \\
\text { with NH8) }\end{array}$ & [14] & $\begin{array}{l}\text { General feature } \\
\text { (design) }\end{array}$ & (3) Useful \\
\hline YH7 & Errors & $\begin{array}{c}\text { Adapt } \\
\text { (separate in two } \\
\text { and join with } \\
\text { NH5 and NH9) }\end{array}$ & [14] & $\begin{array}{l}\text { General feature (error } \\
\text { prevention, recovery } \\
\text { from errors) }\end{array}$ & (2) Important \\
\hline YH8 & Satisfaction & Discard & [14] & - & - \\
\hline YH9 & User suitability & $\begin{array}{l}\text { Adapt (join } \\
\text { with NH7) }\end{array}$ & [14] & $\begin{array}{l}\text { Specific feature } \\
\text { (Customization) }\end{array}$ & (3) Critical \\
\hline YH10 & User language & Discard & [14] & - & - \\
\hline YH11 & User assistance & $\begin{array}{l}\text { Adapt (join } \\
\text { with NH10) }\end{array}$ & [14] & $\begin{array}{l}\text { Specific feature (Help } \\
\text { center) }\end{array}$ & (3) Critical \\
\hline YH12 & Identity signal & Discard & [14] & - & - \\
\hline YH13 & Privacy & Adapt & [14] & $\begin{array}{l}\text { Specific feature } \\
\text { (Security) }\end{array}$ & (3) Critical \\
\hline
\end{tabular}


Table A9. Cont.

\begin{tabular}{|c|c|c|c|c|c|}
\hline ID & Heuristic Name & Action & $\begin{array}{c}\text { Set of } \\
\text { Heuristics }\end{array}$ & Feature Covered & Applicability \\
\hline YH14 & Integrity & Discard & [14] & - & - \\
\hline YH15 & Availability & Adapt & [14] & $\begin{array}{l}\text { Specific feature } \\
\text { (Connectivity) }\end{array}$ & (3) Critical \\
\hline YH16 & Confidentiality & Adapt & [14] & $\begin{array}{l}\text { Specific feature } \\
\text { (Security) }\end{array}$ & (3) Critical \\
\hline EH1 & $\begin{array}{l}\text { Privacy and exhibition } \\
\text { control }\end{array}$ & Adapt & [13] & $\begin{array}{l}\text { Specific feature } \\
\text { (Security) }\end{array}$ & (3) Critical \\
\hline $\mathrm{EH} 2$ & User perception & Adapt & [13] & $\begin{array}{l}\text { Specific feature } \\
\text { (Interaction) }\end{array}$ & (3) Critical \\
\hline EH3 & User status & Adapt & [13] & $\begin{array}{c}\text { Specific feature } \\
\text { (Interaction, Content } \\
\text { management) }\end{array}$ & (3) Critical \\
\hline EH4 & Flexibility & $\begin{array}{l}\text { Adapt (join } \\
\text { with YH9) }\end{array}$ & [13] & $\begin{array}{l}\text { Specific feature } \\
\text { (Customization) }\end{array}$ & (3) Critical \\
\hline EH5 & Control for relationship & Discard & [13] & - & - \\
\hline EH6 & Uniform interface & $\begin{array}{l}\text { Adapt (join } \\
\text { with NH4) }\end{array}$ & [13] & $\begin{array}{l}\text { General feature } \\
\text { (consistency) }\end{array}$ & (2) Important \\
\hline EH7 & Consistency & Discard & [13] & - & - \\
\hline EH8 & Documentation & $\begin{array}{l}\text { Adapt (join } \\
\text { with YH11) }\end{array}$ & [13] & $\begin{array}{l}\text { Specific feature (Help } \\
\text { center) }\end{array}$ & (3) Critical \\
\hline $\mathrm{SNH}$ & $\begin{array}{l}\text { Content control } \\
\text { published }\end{array}$ & New & - & $\begin{array}{c}\text { Specific feature } \\
\text { (Content management) }\end{array}$ & (3) Critical \\
\hline
\end{tabular}

\section{Appendix J}

Table A10. Step 8: "Refinement stage"—iteration 1. Proposed changes for the second iteration.

\begin{tabular}{|c|c|c|}
\hline Heuristic & Problem & Action \\
\hline $\begin{array}{l}\text { SNH2 (Visibility of system elements and } \\
\text { important information). }\end{array}$ & $\begin{array}{l}\text { SNH2 definition is similar to SNH1 } \\
\text { (Visibility of system status). }\end{array}$ & $\begin{array}{l}\text { Eliminate. SNH1 covers the } \\
\text { feature detailed in } \mathrm{SNH} 2 \text {. }\end{array}$ \\
\hline SNH1 (Visibility of system status). & $\begin{array}{l}\text { SNH1 definition is similar to } \mathrm{SNH} 2 \\
\text { (Visibility of system elements and important } \\
\text { information). }\end{array}$ & $\begin{array}{l}\text { Adapt. SNH1 should be } \\
\text { complemented with the } \\
\text { information, detailed in SNH2. }\end{array}$ \\
\hline $\begin{array}{l}\text { SNH6 (Consistency in design and web } \\
\text { symbology). }\end{array}$ & $\begin{array}{l}\text { SNH6 covers the same features } \\
\text { evaluated with SNH5 (Consistency and } \\
\text { standards between system elements). }\end{array}$ & $\begin{array}{l}\text { Eliminate. SNH5 covers the } \\
\text { feature detailed in SNH6. }\end{array}$ \\
\hline $\begin{array}{l}\text { SNH5 (Consistency and standards between } \\
\text { system elements). }\end{array}$ & $\begin{array}{l}\text { SNH5 definition is similar to SNH6 } \\
\text { (Consistency in design and web symbology). }\end{array}$ & $\begin{array}{l}\text { Adapt. SNH5 should be } \\
\text { complemented with the } \\
\text { information, detailed in SNH6. }\end{array}$ \\
\hline $\begin{array}{l}\text { SNH4 (Match between system and the real } \\
\text { world) }\end{array}$ & $\begin{array}{l}\text { The heuristic definition is unclear, } \\
\text { which confuses the user (problems } \\
\text { detected are incorrectly associated). }\end{array}$ & $\begin{array}{l}\text { Refine. The specification should } \\
\text { be improved. }\end{array}$ \\
\hline SNH9 (Minimize the user's memory load) & $\begin{array}{l}\text { The heuristic specification is generic. In } \\
\text { addition, it includes explanations about } \\
\text { the interface design (aspect evaluated by } \\
\text { SNH11), which can generate confusion } \\
\text { and incorrect associations of problems. }\end{array}$ & $\begin{array}{l}\text { Refine. The specification should } \\
\text { be improved. }\end{array}$ \\
\hline SNH14 (Privacy and exposure control) & $\begin{array}{l}\text { The heuristic definition is too long, and } \\
\text { it is difficult to understand what } \\
\text { features it evaluates. }\end{array}$ & $\begin{array}{l}\text { Refine. The specification should } \\
\text { be improved. }\end{array}$ \\
\hline SNH15 (Content control published) & $\begin{array}{l}\text { The heuristic does not clearly explain } \\
\text { the type of control to be carried out on } \\
\text { the information. }\end{array}$ & $\begin{array}{l}\text { Refine. The specification should } \\
\text { be improved. }\end{array}$ \\
\hline SNH1 to SNH16 & $\begin{array}{l}\text { The template of all heuristics must be } \\
\text { complemented, including checklists. }\end{array}$ & $\begin{array}{l}\text { Add more detail to the heuristic's } \\
\text { specification. }\end{array}$ \\
\hline
\end{tabular}




\section{Appendix K}

Table A11. Step 8: "Refinement stage"-iteration 2. Proposed changes for the third iteration.

\begin{tabular}{|c|c|c|}
\hline Heuristic & Problem & Action \\
\hline $\begin{array}{l}\text { SNWH1 (Visibility of elements and } \\
\text { system status) }\end{array}$ & $\begin{array}{l}\text { The heuristic name is unclear, it should be } \\
\text { changed to: Visual feedback and system status. }\end{array}$ & $\begin{array}{l}\text { Refine. The heuristic name and } \\
\text { specification should be improved. }\end{array}$ \\
\hline $\begin{array}{l}\text { SNWH4 (Consistency and standards } \\
\text { between system elements) }\end{array}$ & $\begin{array}{l}\text { The heuristic name is unclear, it should be } \\
\text { changed to: Consistency between platforms. }\end{array}$ & $\begin{array}{l}\text { Refine. The heuristic name and } \\
\text { specification should be improved. }\end{array}$ \\
\hline $\begin{array}{l}\text { SNWH7 (Minimize the user's } \\
\text { memory load) }\end{array}$ & $\begin{array}{l}\text { The heuristic specification is unclear and needs } \\
\text { more details and explanations to help in the } \\
\text { detection of usabilities/UX problems. }\end{array}$ & $\begin{array}{l}\text { Refine. The heuristic specification should be } \\
\text { improved. }\end{array}$ \\
\hline $\begin{array}{l}\text { SNWH9 (Aesthetic and minimalist } \\
\text { design) }\end{array}$ & $\begin{array}{l}\text { The heuristic specification is unclear. In } \\
\text { addition, the heuristic name is not related to the } \\
\text { definition and explanation, it should be } \\
\text { changed to: Design and interface. }\end{array}$ & $\begin{array}{l}\text { Refine. The heuristic name and } \\
\text { specification should be improved. }\end{array}$ \\
\hline SNWH11 (Help and documentation) & $\begin{array}{l}\text { The heuristic name is unclear, it should be } \\
\text { changed to: Help center. }\end{array}$ & $\begin{array}{l}\text { Refine. The heuristic name and } \\
\text { specification should be improved. }\end{array}$ \\
\hline $\begin{array}{l}\text { SNWH12 (Privacy and exposure } \\
\text { control) }\end{array}$ & $\begin{array}{l}\text { The heuristic specification needs more details } \\
\text { and explanations to help in the detection of } \\
\text { usability/UX problems. }\end{array}$ & $\begin{array}{l}\text { Refine. The specification should be } \\
\text { improved. }\end{array}$ \\
\hline $\begin{array}{l}\text { SNWH13 (Content control } \\
\text { published) }\end{array}$ & $\begin{array}{l}\text { The heuristic specification needs more details } \\
\text { and explanations to help in the detection of } \\
\text { usability/UX problems. }\end{array}$ & $\begin{array}{l}\text { Refine. The specification should be } \\
\text { improved. }\end{array}$ \\
\hline $\begin{array}{l}\text { SNWH14 (Security and recovery of } \\
\text { user account) }\end{array}$ & $\begin{array}{l}\text { New elements must be added to the checklist to } \\
\text { better explain the types of usability/UX } \\
\text { problems evaluated by the heuristic. }\end{array}$ & $\begin{array}{l}\text { Refine. The specification should be } \\
\text { improved. }\end{array}$ \\
\hline $\begin{array}{l}\text { SNWH3 (Match between system and } \\
\text { the real world) }\end{array}$ & $\begin{array}{l}\text { The heuristic explanation is unclear, and it is } \\
\text { difficult to use, so it needs more detail in its } \\
\text { specification. }\end{array}$ & $\begin{array}{l}\text { Eliminate. The heuristic is eliminated since: } \\
\text { (1) two of the three usability/UX problems } \\
\text { detected in the heuristic evaluation (first } \\
\text { iteration) were incorrectly associated, and } \\
\text { (2) obtained low values in the dimensions } \\
\text { D2, D3 and D4 in the survey (second } \\
\text { iteration). }\end{array}$ \\
\hline $\begin{array}{l}\text { SNWH8 (Flexibility and efficiency of } \\
\text { use) }\end{array}$ & $\begin{array}{l}\text { The heuristic explanation is unclear, and it is } \\
\text { difficult to use, so it needs more detail in its } \\
\text { specification. }\end{array}$ & $\begin{array}{l}\text { Eliminate. The heuristic is eliminated since: } \\
\text { (1) only one usability/UX problem was } \\
\text { detected in the heuristic evaluation (first } \\
\text { iteration), and it was incorrectly associated, } \\
\text { and (2) obtained low values in the } \\
\text { dimensions D2 and D3 in the survey } \\
\text { (second iteration). }\end{array}$ \\
\hline SNWH6 (Error prevention) & $\begin{array}{l}\text { SNWH6 specification includes aspects that are } \\
\text { evaluated by SNWH10 (Help user to recognize, } \\
\text { diagnose, and recover from errors), so several } \\
\text { usability/UX problems were incorrectly } \\
\text { associated. }\end{array}$ & $\begin{array}{l}\text { Join SNWH6 and SNWH10 and create } \\
\text { SNXH5 (Prevention and recovery from errors). }\end{array}$ \\
\hline $\begin{array}{l}\text { SNWH10 (Help user to recognize, } \\
\text { diagnose, and recover from errors) }\end{array}$ & $\begin{array}{l}\text { SNWH10 specification includes aspects that are } \\
\text { evaluated by SNWH6 (Error prevention), so } \\
\text { several usability/UX problems were incorrectly } \\
\text { associated. }\end{array}$ & $\begin{array}{l}\text { Join SNWH6 and SNWH10 and create } \\
\text { SNXH5 (Prevention and recovery from errors). }\end{array}$ \\
\hline $\begin{array}{l}\text { SNXH5 (Prevention and recovery } \\
\text { from errors) }\end{array}$ & $\begin{array}{l}\text { Many usability/UX problems incorrectly } \\
\text { associated with SNWH6 and SNWH10. }\end{array}$ & $\begin{array}{l}\text { Create. Review SNWH6 and SNWH10 and } \\
\text { specify SNXH5, including the most relevant } \\
\text { elements. }\end{array}$ \\
\hline $\begin{array}{l}\text { SNXH8 (Alert and notification } \\
\text { control) }\end{array}$ & $\begin{array}{l}\text { The "customization" attribute of social } \\
\text { networks is evaluated partially with SNWH set. }\end{array}$ & $\begin{array}{l}\text { Create. Specify SNXH8 to detect specific } \\
\text { usability/UX problems of a social network } \\
\text { related to the customization of alerts and } \\
\text { notifications. }\end{array}$ \\
\hline
\end{tabular}




\section{Appendix L}

Table A12. Step 8: "Refinement stage"-iteration 3. Proposed changes for the fourth iteration.

\begin{tabular}{|c|c|c|}
\hline Heuristic & Problem & Action \\
\hline SNXH2 (Design and interface) & $\begin{array}{l}\text { The heuristic name confuses the evaluator, it } \\
\text { should be changed to: Aesthetic and minimalist } \\
\text { design. }\end{array}$ & $\begin{array}{l}\text { Refine. The heuristic name should be } \\
\text { improved. }\end{array}$ \\
\hline $\begin{array}{l}\text { SNXH9 (Privacy and exposure } \\
\text { control) }\end{array}$ & $\begin{array}{l}\text { The heuristic name is unclear, it should be } \\
\text { changed to: Privacy control. }\end{array}$ & $\begin{array}{l}\text { Refine. The heuristic name and } \\
\text { specification should be improved. }\end{array}$ \\
\hline $\begin{array}{l}\text { SNXH10 (Security and recovery of } \\
\text { user account) }\end{array}$ & $\begin{array}{l}\text { The heuristic explanation does not clearly cover } \\
\text { the recovery of the user account, a critical } \\
\text { element related. }\end{array}$ & $\begin{array}{l}\text { Refine. The heuristic explanation should be } \\
\text { improved. }\end{array}$ \\
\hline $\begin{array}{l}\text { SNXH12 (Consistency between } \\
\text { platforms) }\end{array}$ & $\begin{array}{l}\text { The heuristic evaluates aspects related to } \\
\text { standards in different platforms, but its name } \\
\text { does not indicate it. This makes its name } \\
\text { unclear; it should be changed to: Consistency } \\
\text { and standards in multiplatform. }\end{array}$ & $\begin{array}{l}\text { Refine. The heuristic name and } \\
\text { specification should be improved. }\end{array}$ \\
\hline $\begin{array}{l}\text { SNXH8 (Alert and notification } \\
\text { control) }\end{array}$ & $\begin{array}{l}\text { Very specific heuristic. The heuristic evaluates } \\
\text { only aspects related to notifications and alerts. }\end{array}$ & $\begin{array}{l}\text { Eliminate. Include the aspects evaluated by } \\
\text { SNXH8 in the specification of the new } \\
\text { heuristic SNUXH8 (Flexibility and } \\
\text { customization). }\end{array}$ \\
\hline $\begin{array}{l}\text { SNXH5 (Prevention and recovery } \\
\text { from errors) }\end{array}$ & $\begin{array}{l}\text { The heuristic covers too many usability/UX } \\
\text { problems and may confuse the user. Preventing } \\
\text { mistakes is not the same as recovering from } \\
\text { them. }\end{array}$ & $\begin{array}{l}\text { Separate into SNUXH5 (Error prevention), } \\
\text { and SNUXH9 (Help users recognize, diagnose, } \\
\text { and recover from errors) }\end{array}$ \\
\hline $\begin{array}{l}\text { SNUXH2 (Match between the social } \\
\text { network and real world) (final } \\
\text { version) }\end{array}$ & $\begin{array}{l}\text { Usability/UX problems are detected related to } \\
\text { the intuitive use of elements that do not confuse } \\
\text { the user. These problems are not evaluated by } \\
\text { any heuristic of the SNXH set. }\end{array}$ & $\begin{array}{l}\text { Create. Review the specification of SNWH3 } \\
\text { (Match between system and the real world, } \\
\text { second iteration). Specify SNUXH2, } \\
\text { including the aspects related to intuitive } \\
\text { interfaces (general feature) using SNWH3. }\end{array}$ \\
\hline $\begin{array}{l}\text { SNUXH5 (Error prevention) (final } \\
\text { version) }\end{array}$ & $\begin{array}{l}\text { SNXH5 (Prevention and recovery from errors) } \\
\text { covers too many usability/UX problems and } \\
\text { may confuse the user. Preventing mistakes is } \\
\text { not the same as recovering from them. }\end{array}$ & $\begin{array}{l}\text { Create. Review the specification of SNWH6 } \\
\text { (Error prevention, second iteration), and } \\
\text { SNXH5 (Prevention and recovery from } \\
\text { errors, third iteration). Specify SNUXH5, } \\
\text { including the aspects related to the } \\
\text { prevention of errors (general feature) using } \\
\text { SNWH6 and SNXH5. }\end{array}$ \\
\hline $\begin{array}{l}\text { SNUXH9 (Help users recognize, } \\
\text { diagnose, and recover from errors) } \\
\text { (final version) }\end{array}$ & $\begin{array}{l}\text { SNXH5 (Prevention and recovery from errors) } \\
\text { covers too many usability/UX problems and } \\
\text { may confuse the user. Preventing mistakes is } \\
\text { not the same as recovering from them. }\end{array}$ & $\begin{array}{l}\text { Create. Review the specification of } \\
\text { SNWH10 (Help user to recognize, diagnose, } \\
\text { and recover from errors, second iteration), } \\
\text { and SNXH5 (Prevention and recovery from } \\
\text { errors, third iteration). Specify SNUXH9, } \\
\text { including the aspects related to error } \\
\text { recovery (general feature) using SNWH10 } \\
\text { and SNXH5. }\end{array}$ \\
\hline $\begin{array}{l}\text { SNUXH8 (Flexibility and } \\
\text { customization) (final version) }\end{array}$ & $\begin{array}{l}\text { Problems related to flexibility are not evaluated } \\
\text { by SNXH set. In addition, only the } \\
\text { customization of alerts and notifications is } \\
\text { evaluated by SNXH set. There are more } \\
\text { elements of a social network that can be } \\
\text { customized. }\end{array}$ & $\begin{array}{l}\text { Create. Review the specification of SNWH8 } \\
\text { (Flexibility and efficiency of use, second } \\
\text { iteration), and SNXH8 (Alert and notification } \\
\text { control, third iteration). Specify SNUXH8, } \\
\text { including the aspects related to } \\
\text { customization (specific feature) using } \\
\text { SNWH8 and SNXH8. }\end{array}$ \\
\hline
\end{tabular}

\section{References}

1. GlobalWebIndex. GlobalWebIndex's Flagship Report on the Latest Trends in Social Media. 2018. Available online: https://blog.globalwebindex.com/chart-of-the-day/social-media/ (accessed on 7 July 2020).

2. Ponce, I. Monográfico: Redes Sociales. Instituto Nacional de Tecnologías Educativas y Formación del Profesorado, Spain. 2012. Available online: http://recursostic.educacion.es/observatorio/web/ca/internet/ web-20/1043-redessociales?start=3 (accessed on 7 July 2020).

3. Sundberg, H.-R.; Seppänen, M. Pitfalls in designing and selling UX. In Proceedings of the 18th International Academic MindTrek Conference on Media Business, Management, Content \& Services-AcademicMindTrek'14, Tampere, Finland, 4-6 November 2014; pp. 24-31.

4. Anganes, A.; Pfaff, M.S.; Drury, J.L.; O’Toole, C.M. The Heuristic Quality Scale. Interact. Comput. 2015, 28, 584-597. [CrossRef] 
5. Nielsen, J.; Molich, R. Heuristic evaluation of user interfaces. In Proceedings of the SIGCHI Conference on Human Factors in Computing Systems-CHI'90, Seattle, WA, USA, March 1990; pp. 249-256.

6. Quiñones, D.; Rusu, C.; Rusu, V. A methodology to develop usability/user experience heuristics. Comput. Stand. Interfaces 2018, 59, 109-129. [CrossRef]

7. Quiñones, D.; Rusu, C. Applying a methodology to develop user eXperience heuristics. Comput. Stand. Interfaces 2019, 66, 103345. [CrossRef]

8. Delgado, D.; Zamora, D.; Quiñones, D.; Rusu, C.; Roncagliolo, S.; Rusu, V. User eXperience Heuristics for National Park Websites. In Lecture Notes in Computer Science, Proceedings of the International Social Computing and Social Media. Participation, User Experience, Consumer Experience, and Applications of Social Computing, Conference on Human Computer-Interaction, HCII 2020 vol 12195, Copenhagen, Denmark, 19-24 July 2020; Meiselwitz, G., Ed.; Springer: Berlin/Heidelberg, Germany, 2020; pp. 193-204.

9. Bader, F.; Schon, E.-M.; Thomaschewski, J. Heuristics Considering UX and Quality Criteria for Heuristics. Int. J. Interact. Multimed. Artif. Intell. 2017, 4, 48-53. [CrossRef]

10. Nielsen, J. Ten Usability Heuristics. 1994. Available online: https://www.nngroup.com/articles/tenusabilityheuristics (accessed on 20 July 2020).

11. Quiñones, D.; Rusu, C. How to develop usability heuristics: A systematsic literature review. Comput. Stand. Interfaces 2017, 53, 89-122. [CrossRef]

12. Hermawati, S.; Lawson, G. Establishing usability heuristics for heuristics evaluation in a specific domain: Is there a consensus? Appl. Ergon. 2016, 56, 34-51. [CrossRef] [PubMed]

13. Almeida, R.X.E.D.; Ferreira, S.B.L.; Silveira, D.S.D.; Pimentel, M.; Goldbach, R.; Bessa, A.T. Heurísticas de Usabilidade Orientadas às Redes Sociais. In Proceedings of the IV Encontro de Administração da Informação, Bento Gonçalves, Brazil, 19-21 May 2013.

14. Yeratziotis, A.; Pottas, D.; Greunen, D.V. A usable security heuristic evaluation for the online health social networking paradigm. Int. J. Hum.-Comput. Interact. 2012, 28, 678-694. [CrossRef]

15. Aznal, J.D. Usabilidad en Redes Sociales. Master's Thesis, Universidad Internacional de la Rioja, Madrid, Spain, 2012.

16. Saavedra, M.J.; Rusu, C.; Quiñones, D.; Roncagliolo, S. Social Computing and Social Media, Design, Human Behavior and Analytics, HCII 2019, Lecture Notes in Computer Science. In A Set of Usability and User eXperience Heuristics for Social Networks; Meiselwitz, G., Ed.; Springer: Berlin/Heidelberg, Germany, 2019; Volume 11578, pp. 128-139.

17. Instituto Nacional de Tecnologías de la Comunicación (INTECO). Agencia Española de Protección de Datos. Estudio Sobre la Privacidad de los Datos y la Seguridad de la Información en las Redes Sociales Online, Chapter 2, Spain. February 2009. Available online: https://www.uv.es/limprot/boletin9/inteco.pdf (accessed on 20 July 2020).

18. Boyd, D.M.; Ellison, N.B. Social network sites: Definition, history, and scholarship. J. Comput.-Mediat. Commun. 2007, 13, 210-230. [CrossRef]

19. Urueña, A.; Ferrari, A.; Blanco, D.; Valdecasa, E. Las Redes Sociales en Internet. ONTSI: Observatorio Nacional de las Telecomunicaciones y de la Sociedad de la Información, Spain. 2011. Available online: https: //www.observatoriodelainfancia.es/oia/esp/documentos_ficha.aspx?id=3614 (accessed on 18 September 2020).

20. Sedano, G. Características de las Redes Sociales. Available online: https://www.webespacio.com/ caracteristicas-redes-sociales/ (accessed on 20 July 2020).

21. ISO Standard 9241-210. Ergonomics of Human-System Interaction-Part 11: Usability: Definitions and Concepts, International Organization for Standardization; ISO: Geneva, Switzerland, 2018.

22. Morville, P. User Experience Design. 2004. Available online: http://semanticstudios.com/user_experience_ design/ (accessed on 20 July 2020).

23. Arhippainen, L.; Tähti, M. Empirical Evaluation of User Experience in Two Adaptative Mobile Application Prototypes. In Proceedings of the 2nd International Conference on Mobile and Ubiquitous Multimedia, Norrköping, Sweden, 10-12 December 2003; pp. 27-34.

24. Kankainen, A. Thinking Model and Tools for Understanding User Experience Related to Information Appliance Product Concept; Helsinky University of Technology: Espoo, Finland, 2002.

25. Rusu, C.; Rusu, V.; Roncagliolo, S.; González, C. Usability and user experience: What should we care about? Int. J. Inf. Technol. Syst. Approach IJITSA 2015, 8, 1-12. [CrossRef] 
26. Nielsen, J. Usability 101: Introduction to Usability. 2012. Available online: https://www.nngroup.com/ articles/usability-101-introduction-to-usability/ (accessed on 1 July 2020).

27. All About UX-Information for User Experience Professionals. All UX Evaluation Methods. Available online: http://www.allaboutux.org/all-methods (accessed on 1 July 2020).

28. Nielsen, J. Usability inspection methods. In Proceedings of the Conference Companion on Human Factors in Computing Systems, Boston, MA, USA, 24-28 April 1994; ACM: New York, NY, USA; pp. 413-414.

29. Nielsen, J. Usability Engineering, 1st ed.; Academic Press: San Diego, CA, USA, 1993.

30. Jordan, P. Designing Pleasurable Products: An Introduction to the New Human Factors, 1st ed.; CRC Press: London, UK, 2003.

31. Desmet, P.; Overbeeke, C.; Tax, S. Designing products with added emotional value: Development and application of an approach for research through design. Des. J. 2001, 4, 32-47. [CrossRef]

32. Nielsen, J. How to Conduct a Heuristic Evaluation. 1994. Available online: https://www.nngroup.com/ articles/how-to-conduct-a-heuristic-evaluation/ (accessed on 7 July 2020).

33. Greunen, D.V.; Yeratziotis, A.; Pottas, D. A three-phase process to develop heuristics. In Proceedings of the 13th Annual Conference on WWW Applications (ZA-WWW), Johannesburg, South Africa, August 2011; pp. 14-16.

34. Franklin, F.; Breyer, F.; Kelner, J. Heurísticas de usabilidade para sistemas colaborativos remotos de realidade aumentada. In Proceedings of the XVI Symposium on Virtual and Augmented Reality (SVR), Piata Salvador, Brazil, 12-15 May 2014; pp. 53-62.

35. Hermawati, S.; Lawson, G. A user-centric methodology to establish usability heuristics for specific domains. In Proceedings of the International Conference on Ergonomics \& Human Factors, Daventry, UK, 13-16 April 2015; pp. 80-85.

36. Jimenez, C.; Cid, H.A.; Figueroa, I. PROMETHEUS: Procedural methodology for developing heuristics of usability. IEEE Lat. Am. Tran. 2017, 15, 541-549. [CrossRef]

37. Hub, M.; Čapková, V. Heuristic evaluation of usability of public administration portal. In Proceedings of the International Conference on Applied Computer Science, Malta, 15-17 September 2010; pp. 234-239.

38. Lechner, B.; Fruhling, A.; Petter, S.; Siy, H. The chicken and the pig: User involvement in developing usability heuristics. In Proceedings of the Nineteenth Americas Conference on Information Systems, Chicago, IL, USA, 15-17 August 2013.

39. Rusu, V.; Rusu, C.; Quiñones, D.; Botella, F.; Roncagliolo, S.; Rusu, V.Z. On-Line Travel Agencies' Usability: Evaluator eXperience. In Lecture Notes in Computer Science, Proceedings of theSocial Computing and Social Media, Communication and Social Communities, International Conference on Human Computer-Interaction, HCII 2019, Orlando, FL, USA, 26-31 July 2019; Volume 11579, pp. 452-463.

40. World Wide Web Consortium (W3C). W3C Accessibility Standards Overview. 2019. Available online: https://www.w3.org/WAI/standards-guidelines/ (accessed on 2 July 2020).

(C) 2020 by the authors. Licensee MDPI, Basel, Switzerland. This article is an open access article distributed under the terms and conditions of the Creative Commons Attribution (CC BY) license (http://creativecommons.org/licenses/by/4.0/). 